\title{
Article \\ Body CoM Acceleration for Rapid Analysis of Gait Variability and Pedestrian Effects on Structures
}

\author{
Chiara Bedon $(D$
}

Citation: Bedon, C. Body CoM Acceleration for Rapid Analysis of Gait Variability and Pedestrian Effects on Structures. Buildings 2022, 12, 251. https://doi.org/10.3390/ buildings 12020251

Academic Editor: Elena Ferretti

Received: 13 January 2022

Accepted: 18 February 2022

Published: 21 February 2022

Publisher's Note: MDPI stays neutral with regard to jurisdictional claims in published maps and institutional affiliations.

Copyright: (C) 2022 by the author. Licensee MDPI, Basel, Switzerland. This article is an open access article distributed under the terms and conditions of the Creative Commons Attribution (CC BY) license (https:// creativecommons.org/licenses/by/ $4.0 /)$.
Department of Engineering and Architecture, University of Trieste, 34127 Trieste, Italy; chiara.bedon@dia.units.it

\begin{abstract}
Knowledge of body motion features and walk-induced effects is of primary importance for the vibration analysis of structures, especially low-frequency slabs and lightweight and/or slender systems, as well as for clinical applications. Structurally speaking, consolidated literature procedures are available for a wide set of constructional solutions and typologies. A basic assumption consists in the description of walking humans' effects on structures through equivalent deterministic loads, in which the ground vertical reaction force due to pedestrians depends on their mass and motion frequency. However, a multitude of additional parameters should be taken into account and properly confirmed by dedicated laboratory studies. In this paper, the focus is on the assessment of a rapid analysis protocol in which attention is given to pedestrian input, based on a minimized sensor setup. The study of gait variability and related effects for structural purposes is based on the elaboration of single Wi-Fi sensor, body centre of mass (CoM) accelerations. A total of 50 walking configurations was experimentally investigated in laboratory or in field conditions (for more than 500 recorded gaits), with the support of an adult volunteer. Parametric gait analysis is presented considering different substructure conditions and motion configurations. Body CoM acceleration records are then used for the analysis of a concrete slab, where the attention is focused on the effects of (i) rough experimental body CoM input, or (ii) experimentally derived synthetized gait input. The effects on the structural side of rough experimental walk time histories or synthetized experimental stride signals are discussed.
\end{abstract}

Keywords: vibrations; body center of mass (CoM); vertical acceleration; laboratory experiments; in-field experiments; micro electro-mechanical systems (MEMS) sensor

\section{Introduction}

As is known, special attention is required for the analysis under random walks of possible vibration issues in low-frequency slabs (i.e., with a fundamental vibration frequency lower than $8 \mathrm{~Hz}$ ), or slender and lightweight slabs characterized by limited bending stiffness or even reduced mass, compared to occupants. In this regard, several consolidated calculation approaches can be found in the literature in support of design [1-3].

From a structural point of view, special attention may be required by pedestrian systems which can be more sensitive to walk-induced effects compared to other structural typologies. Traditional vibration serviceability assessment is based on consolidated structural health monitoring procedures and techniques [4-9]. Recently, various studies have started to assess the dynamic behaviour of laminated glass slabs under pedestrians, showing that structural dynamic parameters and performance indicators are rather different from other constructional solutions, as a major effect of flexibility, slenderness and (often) limited mass, compared to occupants [10-13].

When attention is given to the characterization of the effect of walking occupants, however, even more complex calculation models are needed to account for realistic parameters [14-16], and the use of wearable or Wi-Fi sensors can result in efficient support for the analysis. For example, the assumption of a basic inverted pendulum model to describe non-rigid-leg pedestrians (Figure 1a) offers strong insight regarding walking mechanics, 
but also has intrinsic limitations [17]. Many factors are known to typically affect walking features, including age, medical issues, etc. [18], and psychological discomfort [19,20], in addition to dynamic mechanical parameters of the substructure.
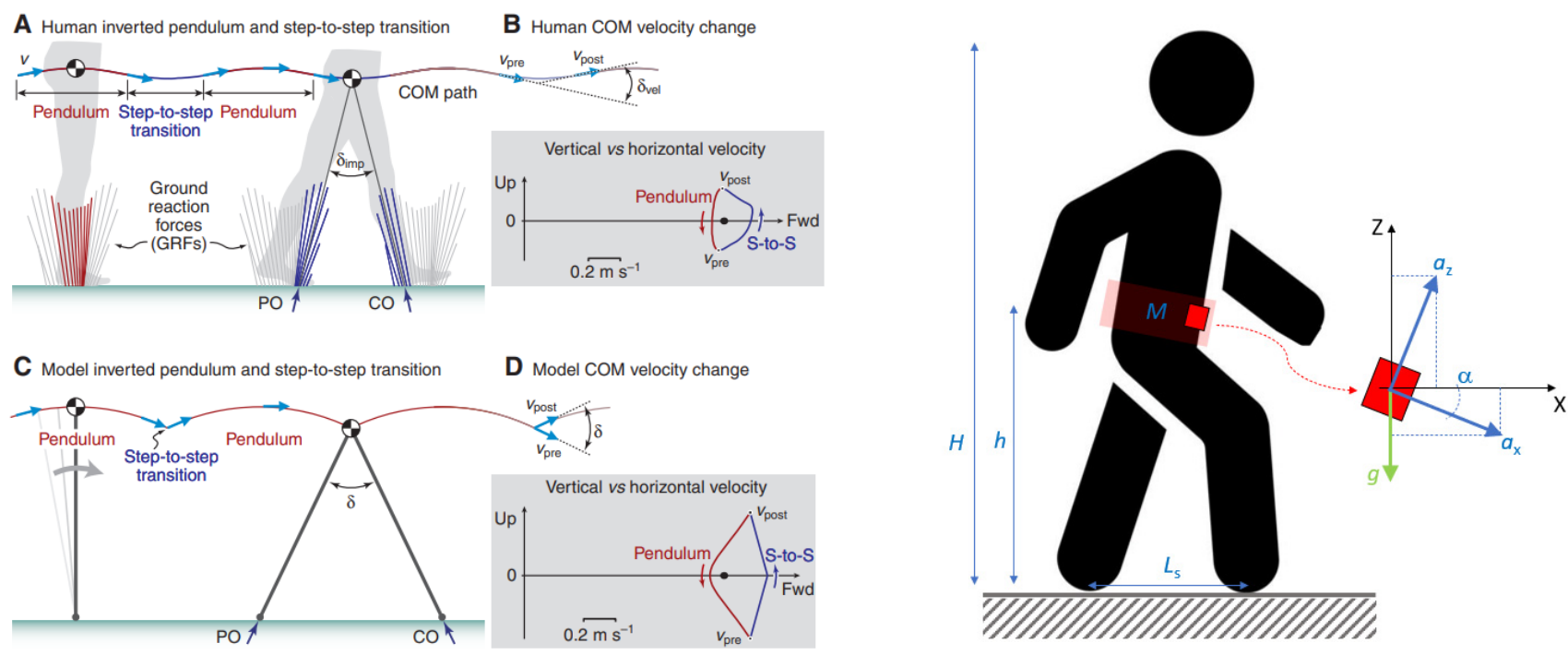

(a)

(b)

Figure 1. Experimental method: (a) reference literature pendulum model (figure reproduced from [17] with permission from The Company of Biologists ${ }^{\circledR}$, order number 1175262, January 2022) and (b) herein adopted measurement system for body CoM acceleration records, with detail of lumbar belt to keep in position the used Wi-Fi sensor.

Among others, the use of various Wi-Fi sensors and instruments, especially accelerometers, has been addressed by several studies to explore the motion variability and features of pedestrians [21-24]. Compared to classical deterministic models to describe loads and ground reaction forces due to pedestrians on structures, there are multiple aspects to take into account. In [25], the use of body centre of mass (CoM) measures was assessed with experimental measures of a volunteer. The optimal use of multiple body sensors to capture motion records for the estimation of the vertical ground reaction force of pedestrians for structural vibration purposes has been assessed in [26]. Bocian et al. [27] demonstrated with experimental studies that a single point inertial measurement can accurately capture the pedestrian vertical induced force, and thus efficiently support the structural vibration analysis process. Different accelerometer locations can offer consistent gait parameters [28]. Smartphone inertial measurement units (IMUs) can also efficiently capture the gait characteristics of pedestrians [29].

In this paper, attention is focused on the analysis of body motion parameters for vibration serviceability assessment of structures, in order to use body measurements for rapid structural evaluation. This is carried out based on rough experimental signals, and by the derivation of synthetized stride signals. More precisely, experimental records are proposed for body CoM of an invited adult volunteer (Figure 1b), with the support of a single high-precision micro electro-mechanical systems (MEMS) sensor, and statistical analysis of acceleration time histories (50 walking configurations, for more than $n_{s}=500$ recorded gaits) is presented. The effects of different substrate conditions (i.e., rigid or flexible slab), different types of shoes, and various motion speed intervals are studied. Correlation analysis is carried out for several walking features, using the linear regression method, to quantify the variability of motion parameters. The experimental body CoM input is then applied to a case-study, low-frequency concrete slab, to quantify the structural vibration effects and address them with respect to conventional loading protocols. 


\section{Background and Goals}

Locomotion mechanics have been investigated by a multitude of research studies, for different purposes. In general terms, the ground reaction force (GRF) and its vertical component (vGRF) are the most meaningful parameters to describe walk and pedestrianinduced effects on structures [6]. Over the years, for structural applications, knowledge of GRF features and trends has facilitated the derivation and calibration of deterministic load models for the reliable description of human-induced effects on pedestrian systems [14]. A major advantage is that the conventional gait effect can be analytically described, as in Figure $2 \mathrm{a}$, and the primary influencing parameter-for a given pedestrian with mass $M$-is represented by the average walking frequency $f_{s}$. For structural analysis, the reference stride module, as in Figure 2a, is repeatedly applied on the structure to cover $n_{s}$ gaits [30]. On the other hand, gait variability and possible irregularities, such as asymmetry, which are typical of normal walks [31], and other aspects, are disregarded. Average vibration effects are, thus, predicted for the structure, disregarding any interaction with pedestrians. Recently, the availability of WiFi or wearable sensors has suggested their use for gait analysis and locomotion studies [27-29]. Three different positions for inertial sensors were considered in [32]. Among others, laboratory studies presented in [26,27] demonstrated that a single inertial sensor in body CoM can capture motion features. The investigation reported in [33] also showed that a single IMU sensor can be efficiently applied to in-field and clinical situations, without the need of dedicated laboratory instruments (i.e., force plates, instrumented treadmills, etc.). Compared to more accurate instrument acquisitions, or multiple sensors, such a possibility represents a major advantage in support of monitoring procedures and diagnostic analyses.

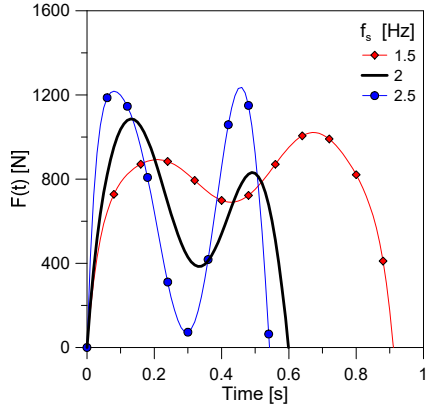

(a)
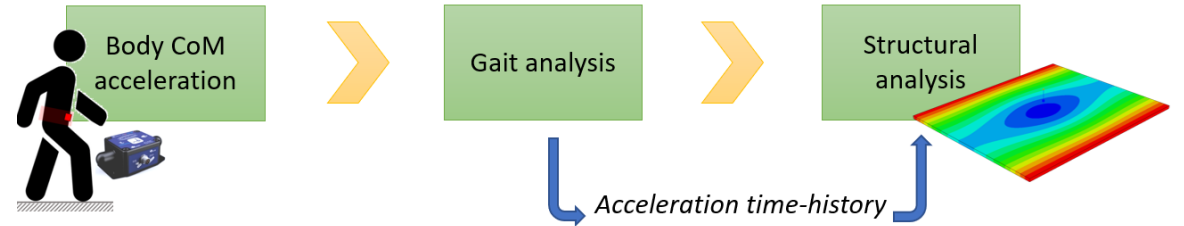

Acceleration time-history

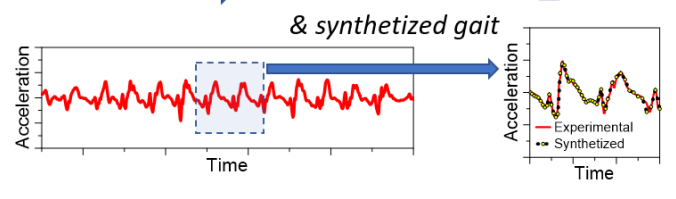

(b)

Figure 2. Gait variability and walk-induced effects on structures based on (a) deterministic loads (examples of gait-induced loads for different walking frequencies $f_{s}$ ) or $(\mathbf{b})$ present procedure.

According to Figure 1 and the literature, the present investigation takes advantage of the fact that the vertical force transferred by a pedestrian on a substructure can be estimated from Newton's second law of motion, in which the body CoM-induced dynamic term can be expressed as:

$$
F(t)=M a_{Z}(t)
$$

When a single Wi-Fi sensor is used as in Figure 1b, experimental records can be disconnected from any kind of laboratory setup, and can thus facilitate the definition of a rapid protocol for diagnostic and structural assessment purposes.

The proposed analysis follows the concept layout in Figure $2 \mathrm{~b}$, where body CoM accelerations are explored to find correlations in locomotion indicators, and successively elaborated to derive basic input for structural analysis. Attention is given to (i) extended walking paths (i.e., with variable motion speed) and (ii) synthetized modular gaits. The accuracy of such a procedure is quantified based on numerical comparisons of dynamic performance indicators for a case-study concrete slab [30], calculated as from (i) or (ii) input, or even (iii) a deterministic loading protocol, as in Figure 2a. 


\section{Experimental Investigation}

\subsection{Instruments and Setup}

The present experimental study involved a single volunteer (38-year female, $M=80 \mathrm{~kg}$, $H=1.85 \mathrm{~m}, h=1.10 \mathrm{~m}$ ) asked to walk while using a high-precision, Wi-Fi triaxial sensor to track acceleration and inclination time histories (BeanDevice ${ }^{\circledR}$ WiLow ${ }^{\circledR}$ type [34] based on micro electro-mechanical systems (MEMS) technology for structural health monitoring). The sampling rate was set at $200 \mathrm{~Hz}$ and a lumbar belt was used to keep the sensor in position during body motion (Figure $1 \mathrm{~b}$ ).

In total, 50 walk patterns were measured under various movement frequencies $f_{s}$ (W1 to W5 in Table 1). The volunteer was asked to walk naturally and to keep a rather constant speed for each test repetition. For each walking configuration, a minimum of $n_{s, \min }=10$ steps was taken into account as a reference (average steps can be seen in Table 1). Such an assumption resulted in a total of more than $n_{s}=500$ recorded gaits to post-process for structural vibration analysis. Moreover, this choice allowed recording to be started from a resting position, with progressive increase in the motion speed and successively reaching a final position at rest (Figure 3).

Table 1. Set of walking configurations for experimental acquisitions. SLAB\#1 = rigid (laboratory) SLAB\#2 = flexible (in-field).

\begin{tabular}{|c|c|c|c|c|c|}
\hline & Samples & Walk & $\begin{array}{c}\text { Steps (avg) } \\
n_{s}\end{array}$ & Substructure & Shoes/Features \\
\hline W0 & 2 & Straight & 14 & SLAB\#1 \& \#2 & S1/GRIP outsoles + heel air cushions (low hiking) \\
\hline W1 & 10 & Straight & 15 & SLAB\#1 & $\mathrm{S} 2 /$ Croslite $^{\mathrm{TM}}$ resin \\
\hline W2 & 10 & Straight & 15 & SLAB\#1 & $\mathrm{S} 2 /$ Croslite $^{\mathrm{TM}}$ resin \\
\hline W3 & 10 & Straight & 12 & SLAB\#1 & $\mathrm{S} 3 /$ Kalensole $^{\mathrm{TM}}$ foam (running) \\
\hline W4 & 10 & Straight & 13 & SLAB\#1 & S4/Sneakers \\
\hline W5 & 10 & In-place & 12 & SLAB\#1 & $\mathrm{S} 2 /$ Croslite $^{\mathrm{TM}}$ resin \\
\hline
\end{tabular}

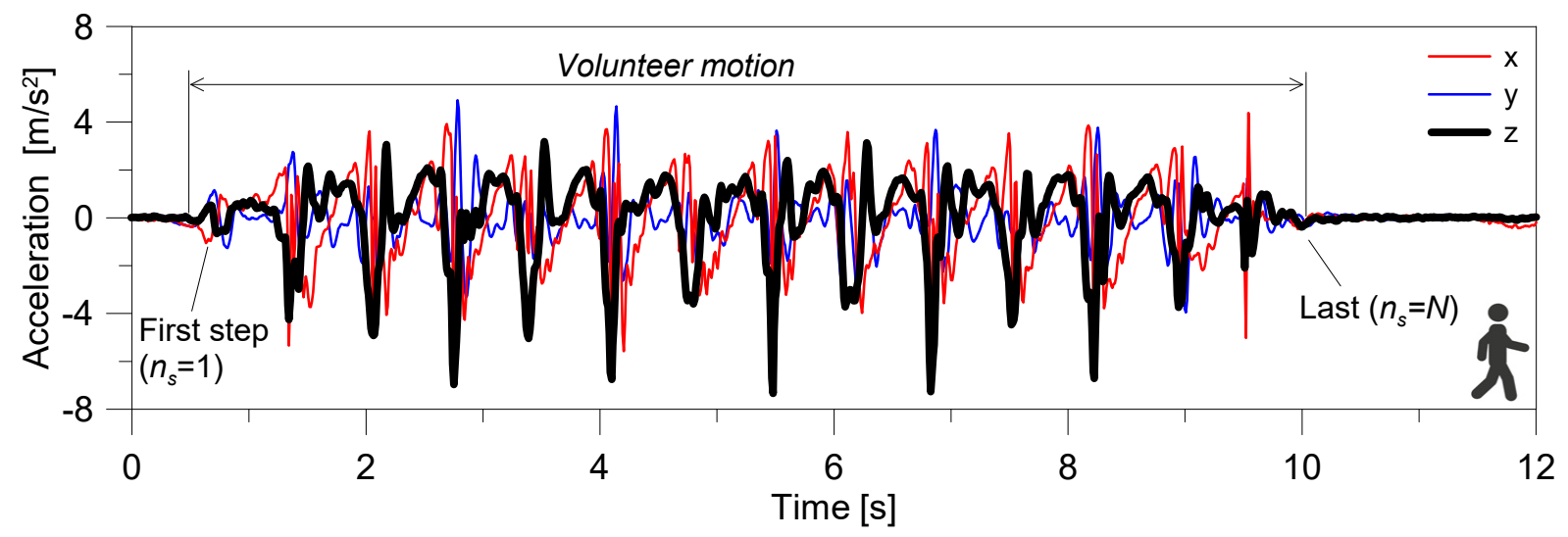

Figure 3. Example of experimental records for body CoM accelerations in time.

In doing so, under the limited condition of a single volunteer for the whole investigation, the experimental program evaluated some potential influencing parameters on walk features. Different types of shoes were used throughout the study, and randomly distributed during the repetition of measurements (S1 to S4 types in Table 1). Most importantly, W0 signals of Table 1 were collected for the invited volunteer who was asked to walk with constant speed above two different substructures, corresponding to a rigid concrete foundation (SLAB\#1) or a flexible slab system (SLAB\#2). This was obtained in laboratory conditions for SLAB\#1 (Figure 4a) or based on in-field records for SLAB\#2 (Figure 4b). Finally, a last set of records (W5 in Table 1) was collected during in-place/stationary walks of the volunteer. 


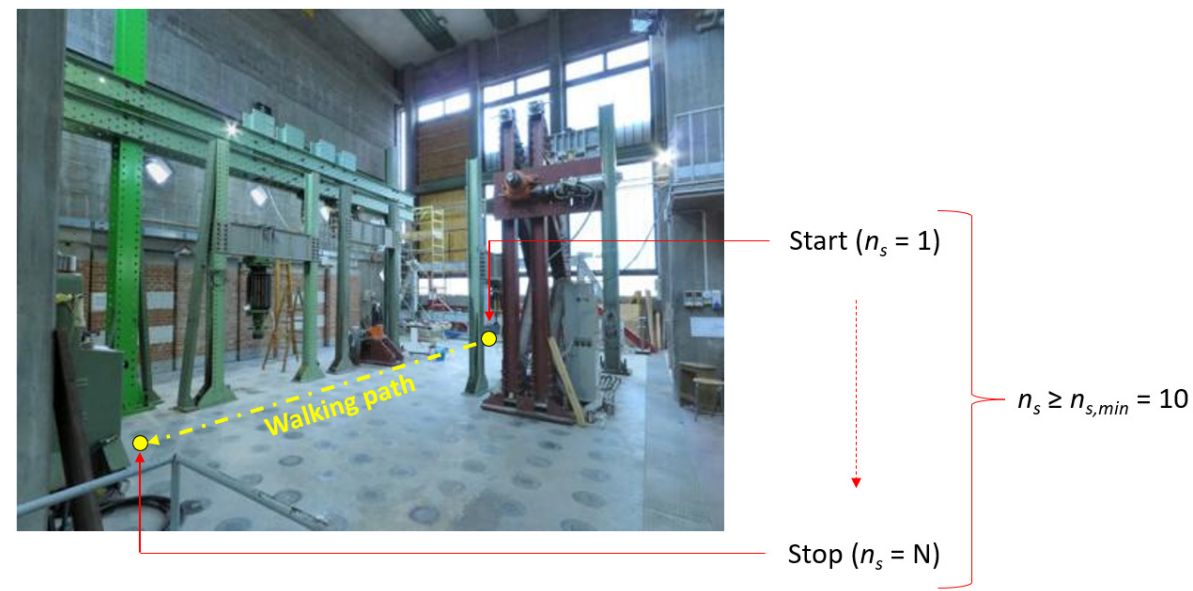

(a)
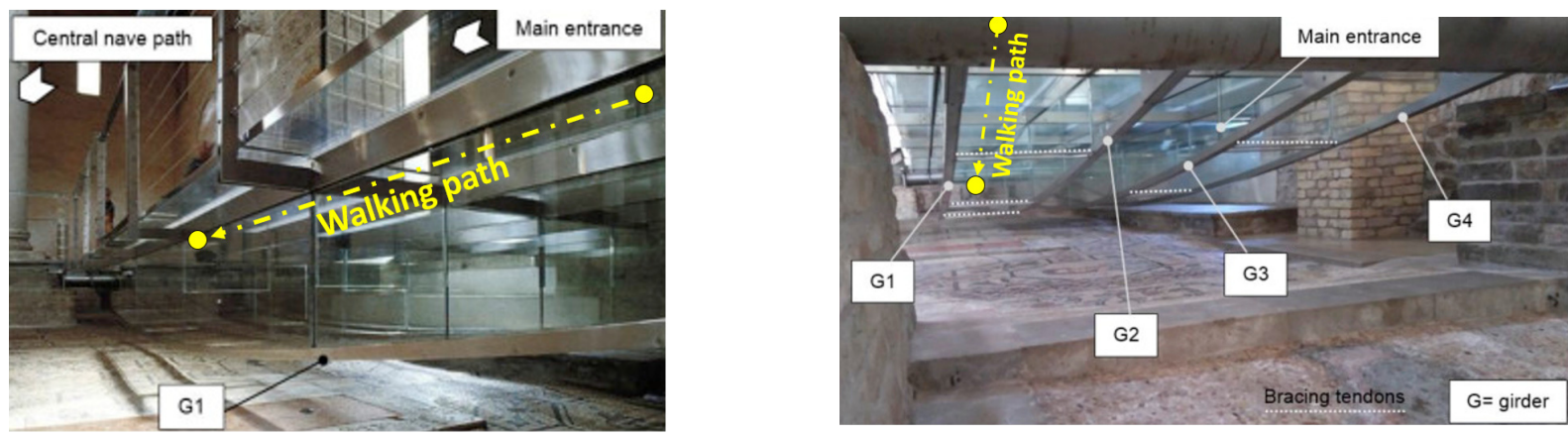

(b)

Figure 4. Reference (a) rigid concrete floor (SLAB\#1) and (b) flexible glass SLAB\#2 system for W0 body CoM measures (figure (b) adapted from [10] with permission from Elsevier ${ }^{\circledR}$, license agreement n. 5223670279902, January 2022).

Assuming the MEMS sensor oriented as in Figure 1b, the vertical acceleration component $a_{Z}(t)$ during walks was first calculated taking into account the sensor inclination due to body movements, thus:

$$
a_{Z}(t)=a_{z}(t) \cos \alpha(t)-a_{x}(t) \sin \alpha(t)
$$

Following Equation (1), the calculated output of Equation (2) was elaborated as primary input for gait analysis and structural performance assessment. A typical body CoM output is proposed in Figure 3, with evidence of acceleration components.

\subsection{Derivation of Motion Parameters}

All the experimental records collected as in Section 3.1 were elaborated to calculate the corresponding walking frequency $f_{s}$ and other relevant motion parameters. The gait length $L_{S}$ was calculated on the basis of covered distance $(L)$, divided by the number of steps $n_{s}$, for each test repetition:

$$
L_{S}=\frac{L}{n_{S}}
$$

The walking speed $v_{s}$ was measured based on average values as:

$$
v_{S}=L_{S} f_{S}
$$

while the stride interval $s_{i}$ (in seconds) was defined as in Figure 5a. 


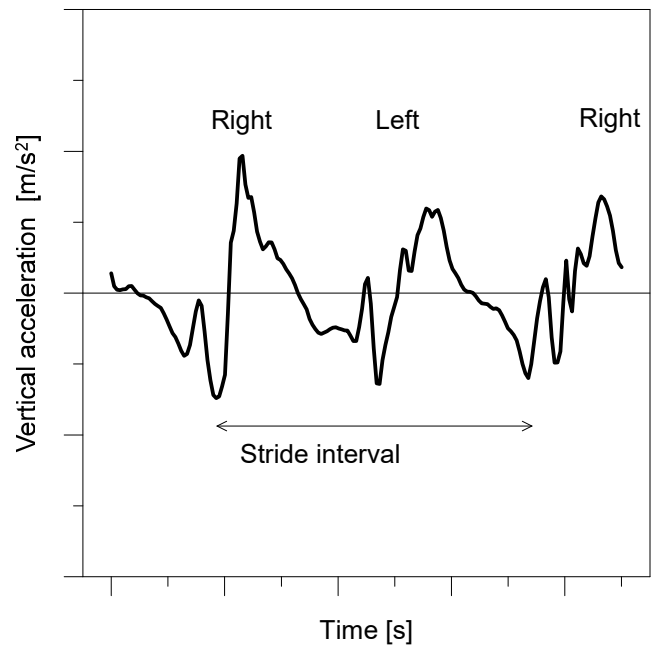

(a)

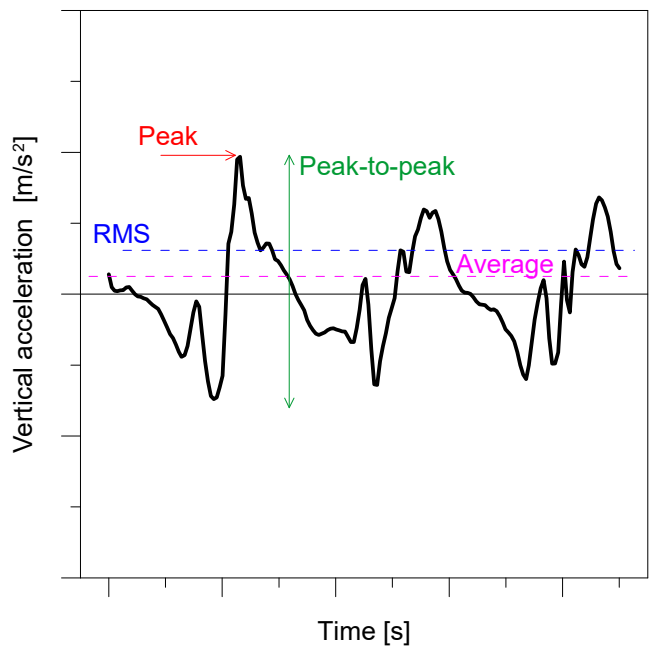

(b)

Figure 5. Analysis of body CoM records: example of (a) stride interval definition and (b) reference acceleration parameters.

According to Figure $5 b$, additional gait parameters included - with special attention to the vertical direction - the derivation for each record of the absolute acceleration value $\left(a_{Z, \max }\right)$, the peak-to-peak value $\left(a_{Z p-p}\right)$, the average value $\left(a_{Z, a v g}\right)$, and the RMS value:

$$
a_{Z, R M S}=\sqrt{\frac{1}{t_{n}-t_{n-1}} \int_{t_{n-1}}^{t_{n}} a_{Z}^{2}(t) d t}
$$

\section{Analysis of Experimental Signals}

\subsection{Substructure (W0)}

Preliminary measurement was carried out when the volunteer was asked to walk on the rigid floor (SLAB\#1) and on the flexible slab system (SLAB\#2), as reported in Figure 4. These measurements were carried out for the volunteer equipped with the same shoes (S1 type), and asked to walk naturally, with a rather uniform gait length, frequency and in a straight path.

The rigid SLAB\#1 setup was designed to coincide with the laboratory environment in Figure $4 \mathrm{a}$, which consisted of a massive $80 \mathrm{~cm}$ thick reinforced concrete contrast floor. For the analysis of body CoM accelerations on SLAB\#2, the suspension laminated glass walkway already investigated in [10], and reproduced in Figure $4 \mathrm{~b}$, was taken into account for in-field measurements. The structure consisted of a composite slab in which the laminated glass section layout included three $12 \mathrm{~mm}$ thick glass panels and interposed PVB $^{\circledR}$ foils (0.76 mm thick). An additional glass layer, $6 \mathrm{~mm}$ in thickness, was used to protect the laminated section. The glass panels were linearly supported along the edges by a metal grid composed of C-shaped steel members. Such a solution was used to cover a total surface of $14.5 \mathrm{~m} \times 2.8 \mathrm{~m}$. The overall slab system was then sustained by four longitudinal steel-glass girders, spanning over the full bending length of $14.5 \mathrm{~m}$. Most importantly, the flexible SLAB\#2 system was characterized by a total mass for glass panels of the order of $M_{\text {glass }} \approx 4020 \mathrm{~kg}$ and a vibration frequency $f_{1, e}=7.28 \mathrm{~Hz}$ (experimental measure for the empty structure [10]).

Typical experimental acquisitions from W0 walking configurations on SLAB\#1 or SLAB\#2 can be seen in Figure 6, divided by the acceleration component as a function of time. The average walking frequency was measured as $f_{s}=1.46 \mathrm{~Hz}$, which corresponds to conventional slow motion. It is easy to see the progressive increase in acceleration peaks from rest, as well as the typical trend of acceleration modules corresponding to each gait. 
Each W0 walk consisted of $n_{s}=15$ gaits and was calculated at a walking speed $v \approx 1 \mathrm{~m} / \mathrm{s}$ $(0.983 \mathrm{~m} / \mathrm{s})$, with $L_{s}=0.67 \mathrm{~m}$ the average gait length.

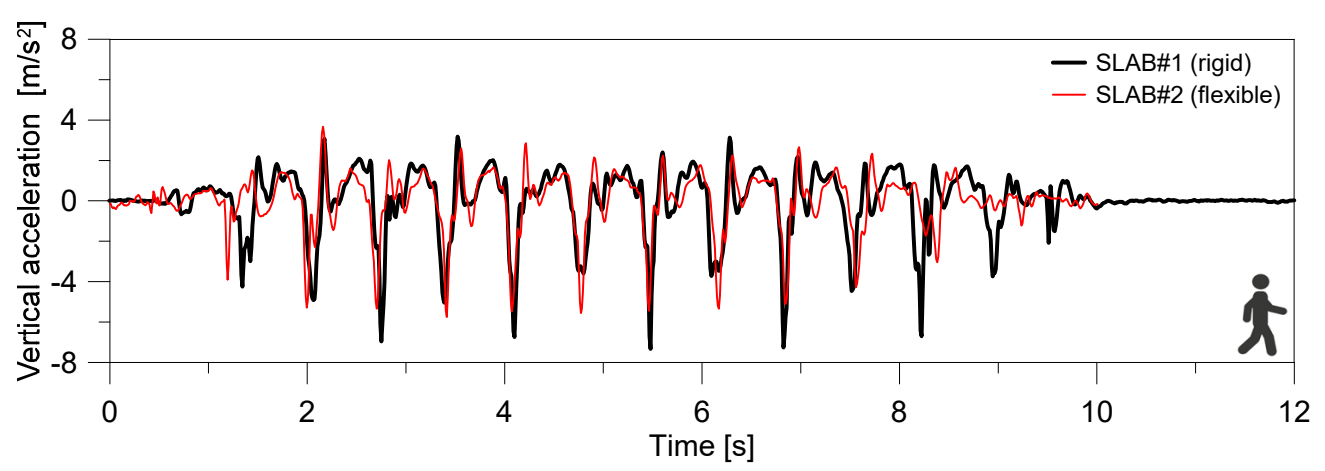

(a)

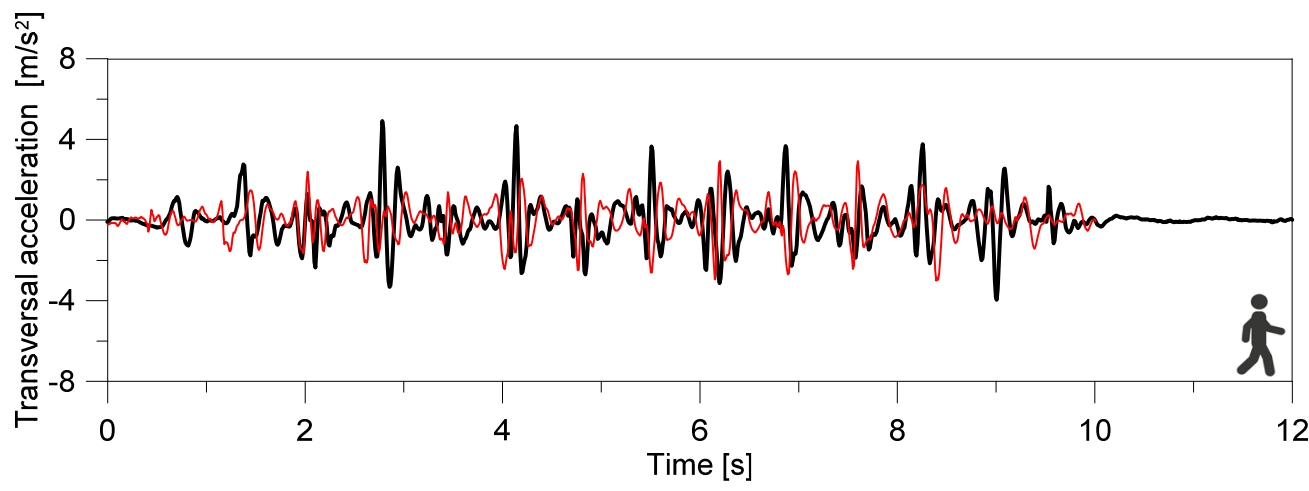

(b)

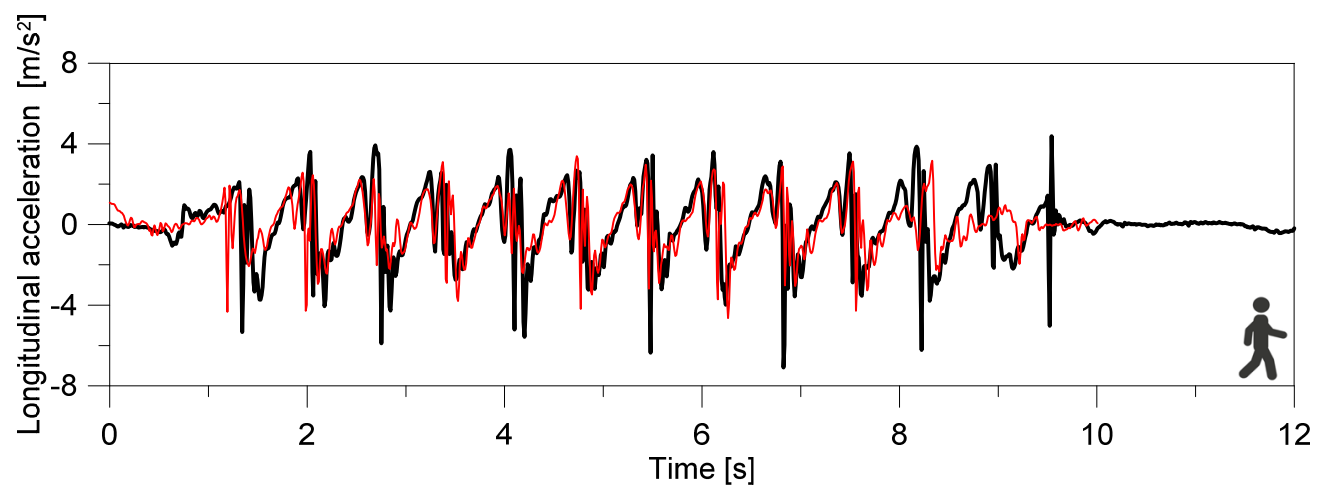

(c)

Figure 6. Example of experimental body CoM accelerations in time (W0 setup) for the volunteer moving on a rigid slab (SLAB\#1) or a flexible substructure (SLAB\#2).

Especially for the vertical acceleration component, which is of primary interest for the present study, limited modifications of acceleration records can be noticed for the volunteer walking on SLAB\#1 or \#2. The RMS values were calculated as $0.441 \mathrm{~m} / \mathrm{s}^{2}$ and $0.444 \mathrm{~m} / \mathrm{s}^{2}$, respectively. For SLAB\#1, the vertical acceleration peak (absolute value) was measured as $a_{Z, \max }=7.33 \mathrm{~m} / \mathrm{s}^{2}\left(a_{Z, a v g}=0.00086 \mathrm{~m} / \mathrm{s}^{2}\right)$, with a maximum peak-to-peak value $a_{Z, p-p}=10.52 \mathrm{~m} / \mathrm{s}^{2}$. For SLAB\#2, the walking records resulted in $a_{Z, \max }=5.76 \mathrm{~m} / \mathrm{s}^{2}$, $a_{Z, a v g}=0.0041 \mathrm{~m} / \mathrm{s}^{2}$ and $a_{Z, p-p}=9.43 \mathrm{~m} / \mathrm{s}^{2}$. Body CoM acceleration trends were thus found to be rather uniform in time but with slightly more pronounced peaks in the presence of the rigid substructure (SLAB\#1). The peak-to-peak value was calculated for SLAB\#1 up to $+11.5 \%$ compared to SLAB\#2 (+27\% for the absolute maximum value).

High sensitivity can be noticed in Figure $6 \mathrm{~b}$ for the transversal component of $\mathrm{CoM}$ acceleration, which was more severely affected by body motion. Maximum acceleration 
peaks were also higher for SLAB\#1 in terms of transversal and longitudinal acceleration, due to different interaction effects of the volunteer with the substrate.

The post-processing fast transform analysis of signals in Figure 7 further confirms the rather good agreement of trends but with limited peaks for walks on flexible SLAB\#2.

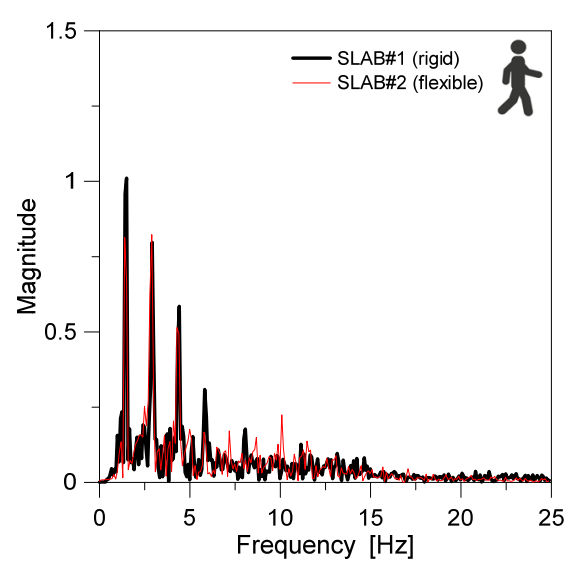

(a)

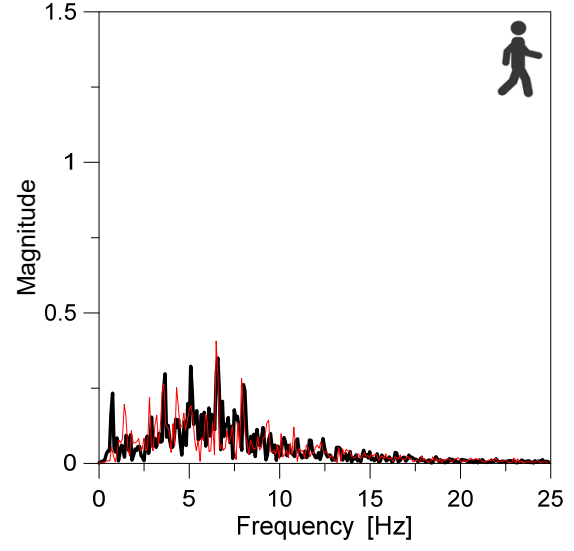

(b)

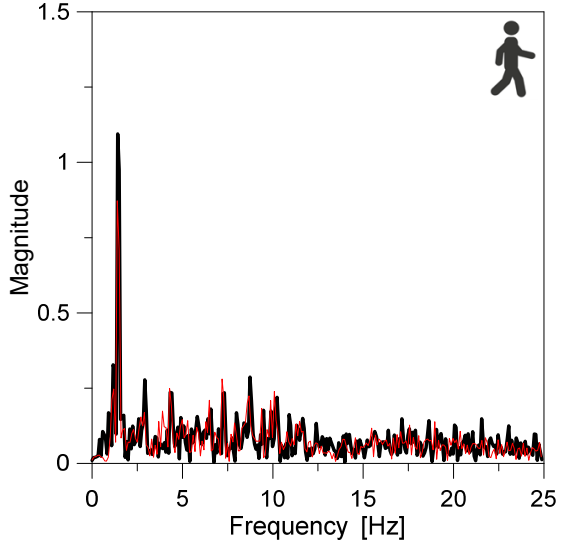

(c)

Figure 7. Analysis of experimental body CoM acceleration records (W0 signals) in terms of fast transform magnitude, with evidence of (a) vertical, (b) transversal, and (c) longitudinal components.

\subsection{Straight Walks (W1 to W4)}

Acceleration measures from linear walk patterns, as for the W1 to W4 schemes in Table 1, were successively analysed. Typical records were found to present several modifications in signal content and trend (see for example Figure 8, W2_2 signal).

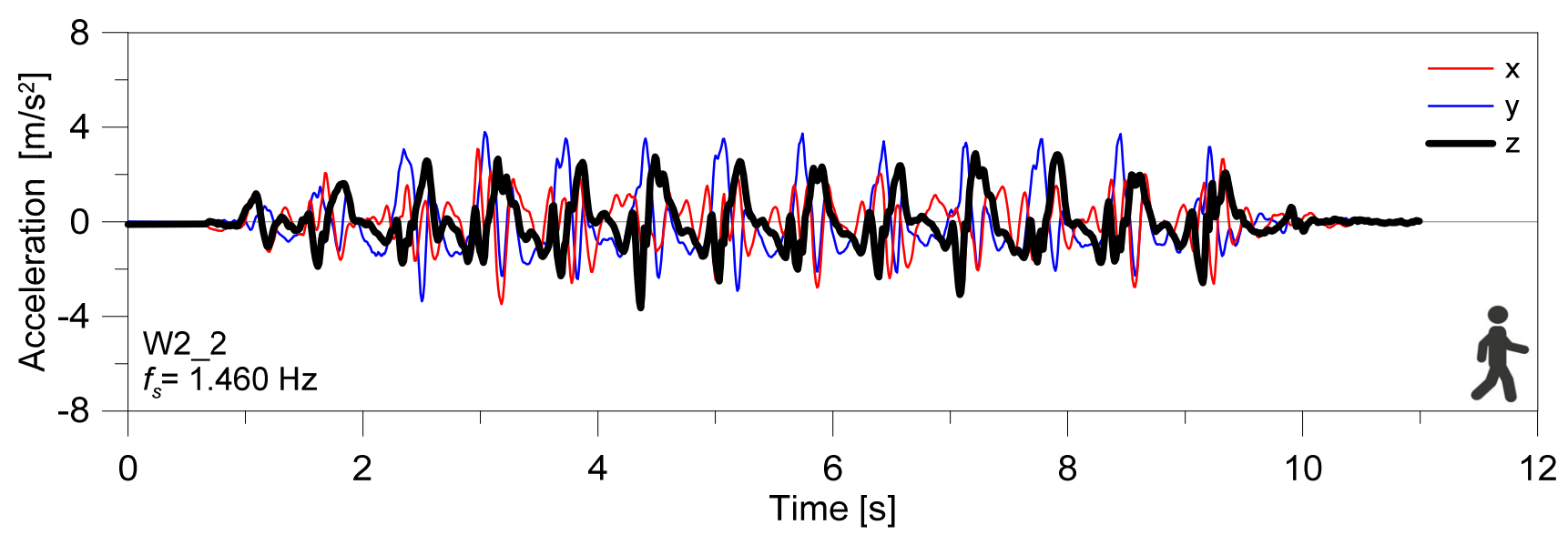

Figure 8. Example of experimental body CoM accelerations in time (W2 selection) for the volunteer moving on SLAB\#1.

As reported in Figure 9, for the selected W2_2 signal (with $f_{s}=1.460 \mathrm{~Hz}$ ) and W3_1 signal (with $f_{s}=1.433 \mathrm{~Hz}$ ), while being characterized by similar walking frequency for the invited volunteer, multiple experimental signals were found to be associated with a certain scatter in magnitude and trend. This suggests that walking frequency $f_{s}$ alone does not allow the obtaining of an unequivocal description of corresponding motion for a given pedestrian with mass $M$. 


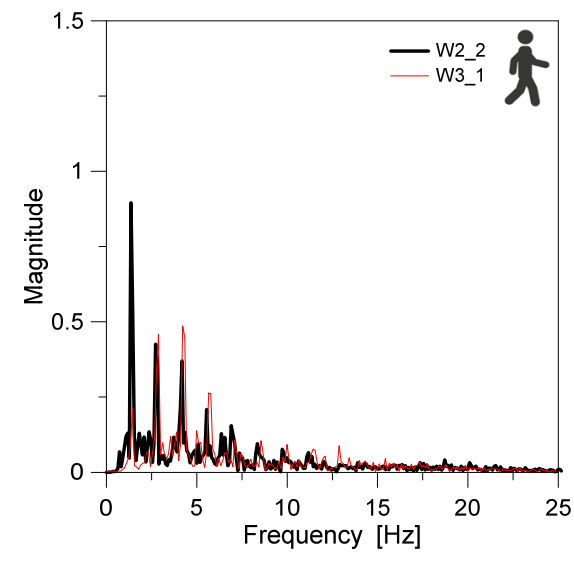

(a)

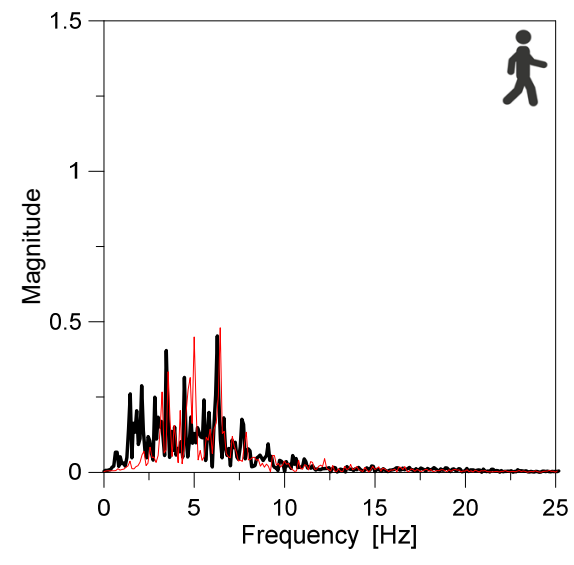

(b)

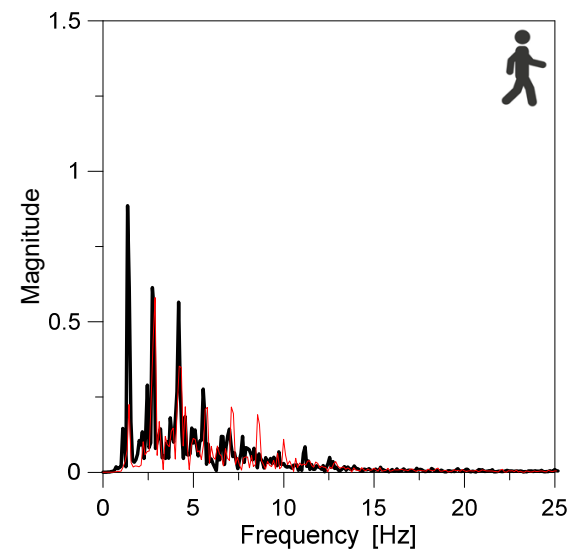

(c)

Figure 9. Analysis of experimental body CoM acceleration records (W2-W3 selection) in terms of fast transform magnitude, with evidence of (a) vertical, (b) transversal, and (c) longitudinal components.

In this regard, a summary of experimental outcomes for W1-to-W4 configurations (40 records) is shown in Figure 10. The average walking frequency was measured as $1.51 \mathrm{~Hz}$ $( \pm 0.16 \mathrm{~Hz}$, with $p$-value $=0.012)$, see Figure 10a.

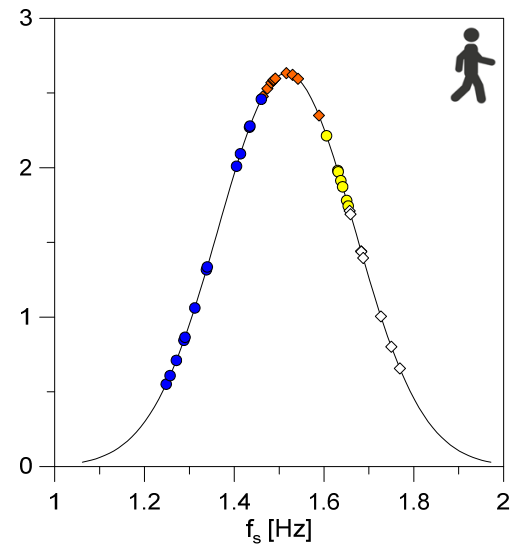

(a)

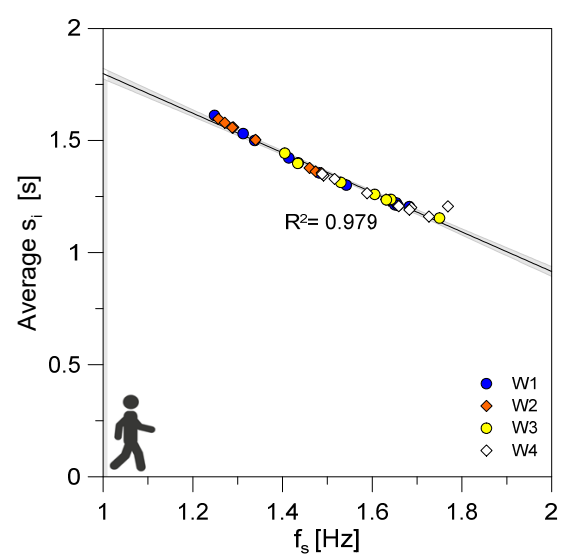

(d)

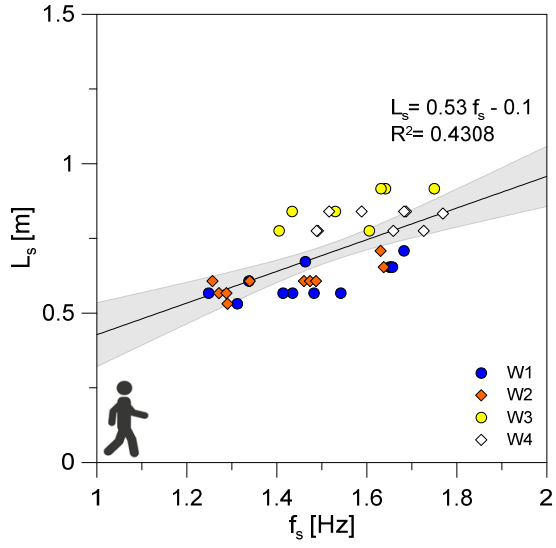

(b)

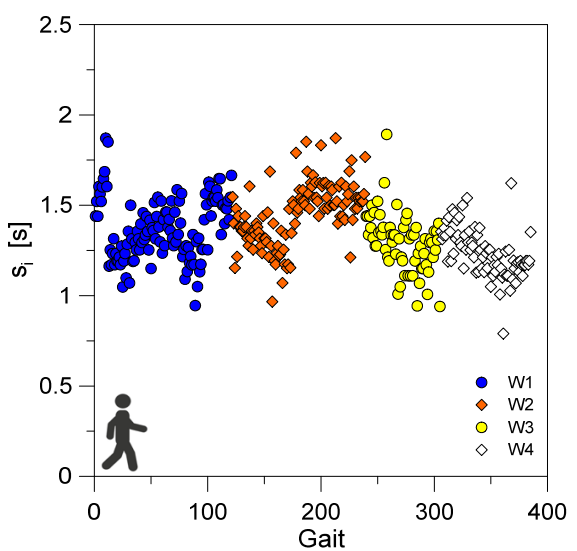

(e)

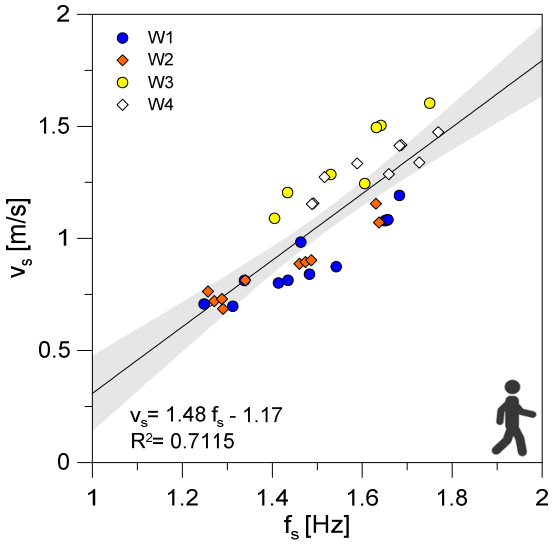

(c)
Figure 10. Summary of experimental records for W1-W4 configurations: (a) Gaussian distribution of samples (40 in total), (b) stride length, (c) walking speed, (d) average stride interval, (e) stride interval variation. The $95 \%$ confidence interval is shown in grey colour. 
Further walking characteristics are proposed in Figure $10 \mathrm{~b}-\mathrm{d}$, as a function of $f_{s}$. A linear regression model is also presented, with evidence of $R^{2}$ values, to analyse motion features. The grey fill shows the corresponding $95 \%$ confidence interval. The stride interval, calculated as in Figure 4a, is shown in Figure 10e for all the collected records. The mean value was estimated in $s_{i, a v g}=1.354 \mathrm{~s}$. Regarding the acceleration trend and peaks for the same experimental records, comparative results are summarized in Figure 11 for the vertical component. Additional comparative analysis of collected body CoM data is also presented in Tables 2 and 3.

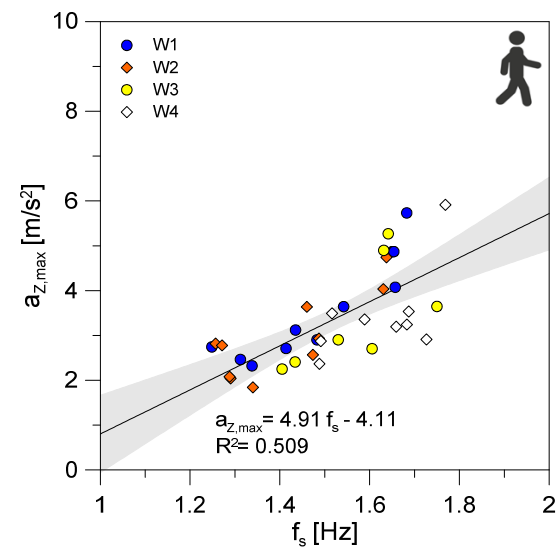

(a)

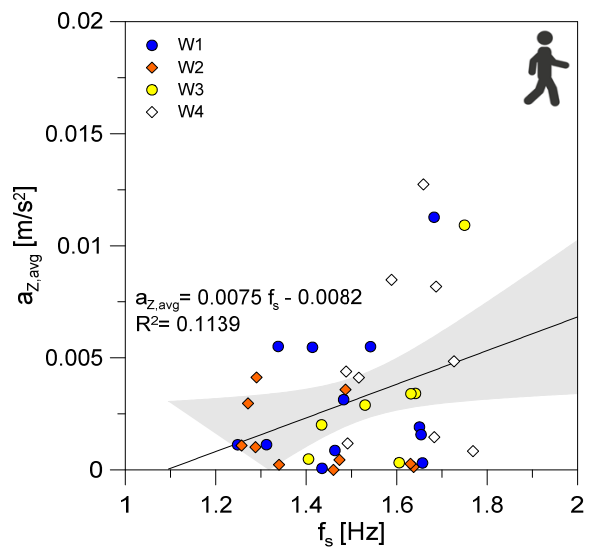

(b)

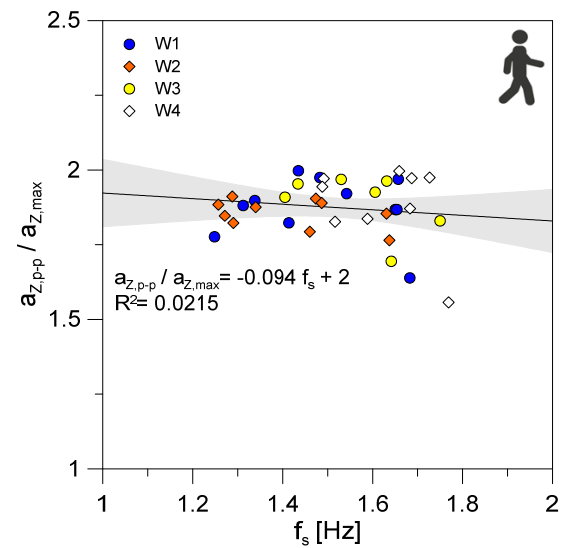

(c)

Figure 11. Summary of experimental records for W1-W4 configurations, as a function of calculated walking frequency: (a) peak of vertical acceleration, (b) average vertical acceleration, (c) peak-to-peak versus maximum acceleration. The $95 \%$ confidence interval is shown in grey colour.

Table 2. Analysis of W1-to-W4 features (SLAB\#1), with standard deviation in brackets and correlation coefficient $R$.

\begin{tabular}{cccccccc}
\hline & \multicolumn{2}{c}{ Frequency } & \multicolumn{2}{c}{ Length } & \multicolumn{2}{c}{ Velocity } \\
\hline & Samples & $\begin{array}{c}f_{s} \\
{[\mathbf{H z}]}\end{array}$ & $\begin{array}{c}\text { Range } \\
{[\mathbf{H z}]}\end{array}$ & $\begin{array}{c}\boldsymbol{L}_{\boldsymbol{s}} \\
{[\mathbf{m}]}\end{array}$ & $\boldsymbol{R}$ & $\begin{array}{c}\boldsymbol{V} \\
{[\mathbf{m} / \mathbf{s}]}\end{array}$ & $\boldsymbol{R}$ \\
\hline W1 & 10 & $1.492( \pm 0.156)$ & $1.248-1.683$ & $0.604( \pm 0.055)$ & 0.80 & $0.907( \pm 0.171)$ & 0.95 \\
W2 & 10 & $1.414( \pm 0.145)$ & $1.257-1.637$ & $0.607( \pm 0.049)$ & 0.83 & $0.862( \pm 0.154)$ & 0.96 \\
W3 & 10 & $1.571( \pm 0.122)$ & $1.405-1.750$ & $0.854( \pm 0.064)$ & 0.69 & $1.346( \pm 0.189)$ & 0.92 \\
W4 & 10 & $1.623( \pm 0.106)$ & $1.488-1.769$ & $0.810( \pm 0.033)$ & 0.26 & $1.316( \pm 0.138)$ & 0.88 \\
\hline Total & 40 & $1.517( \pm 0.153)$ & $1.248-1.769$ & $0.702( \pm 0.124)$ & 0.66 & $1.078( \pm 0.270)$ & 0.84 \\
\hline
\end{tabular}

Table 3. Analysis of W1-to-W4 vertical acceleration data (SLAB\#1), with standard deviation in brackets and correlation coefficient $R$.

\begin{tabular}{|c|c|c|c|c|c|c|c|c|}
\hline & \multirow[b]{2}{*}{ Samples } & \multicolumn{3}{|c|}{ Peak } & \multicolumn{2}{|c|}{ Average } & \multicolumn{2}{|c|}{ Peak-to-Peak } \\
\hline & & $\begin{array}{l}a_{Z, \max } \\
{\left[\mathrm{m} / \mathrm{s}^{2}\right]}\end{array}$ & $\begin{array}{l}\text { Range } \\
{\left[\mathrm{m} / \mathrm{s}^{2}\right]}\end{array}$ & $R$ & $\begin{array}{c}a_{Z, a v g} \\
{\left[\mathrm{~m} / \mathrm{s}^{2}\right]}\end{array}$ & $R$ & $\begin{array}{c}a_{Z, p-p} \\
{\left[\mathrm{~m} / \mathrm{s}^{2}\right]}\end{array}$ & $R$ \\
\hline W1 & 10 & $3.586( \pm 1.147)$ & $2.322-5.733$ & 0.90 & $0.0033( \pm 0.003)$ & 0.24 & $6.674( \pm 1.941)$ & 0.95 \\
\hline W2 & 10 & $2.947( \pm 0.935)$ & $1.840-4.743$ & 0.81 & $0.0013( \pm 0.002)$ & -0.42 & $5.438( \pm 1.613)$ & 0.82 \\
\hline W3 & 10 & $3.439( \pm 1.213)$ & $2.249-5.268$ & 0.66 & $0.0033( \pm 0.004)$ & 0.74 & $6.447( \pm 2.081)$ & 0.65 \\
\hline W4 & 10 & $3.431( \pm 0.999)$ & $2.366-5.913$ & 0.60 & $0.0051( \pm 0.004)$ & 0.06 & $6.353( \pm 1.253)$ & 0.67 \\
\hline Total & 40 & $3.348( \pm 1.057)$ & $1.840-5.913$ & 0.71 & $0.0032( \pm 0.003)$ & 0.34 & $6.219( \pm 1.736)$ & 0.75 \\
\hline
\end{tabular}


From comparative data in Figure 11 and Tables 2 and 3, it is possible to see a large variation in walking parameters from the involved volunteer. The overall trend of vertical acceleration peak from body CoM motion had a weak correlation with walking frequency $\left(R^{2}=0.509\right.$, Figure 11a), while the average vertical acceleration was measured at less than $0.015 \mathrm{~m} / \mathrm{s}^{2}$. (Figure $11 \mathrm{~b}$ ).

Finally, the peak-to-peak versus maximum ratio was calculated to be of the order of $\approx 1.8$, but with high sensitivity to walking configurations and with a rather scattered distribution (Figure 11c). The best correlation of body CoM records with walking frequency was generally found for the W1 and W2 sets (with lower average $f_{s}$ ) for stride length and speed in Table 2, but also for vertical acceleration trends in Table 3. The exception is represented by average acceleration values in Table 3, which were calculated from the CoM position at rest, and thus do not provide useful feedback for analysis. The peak-to-peak value, for all the tested scenarios, was generally found to be of the order of less than twice the absolute peak of vertical acceleration.

Regarding the transversal acceleration of body CoM during walks, the experimental records showed that maximum peaks can be relevant and higher than in the vertical direction, and thus more complex biomechanical models should be considered, in addition to the vertical component only. For the present study, transversal acceleration peaks were found to exceed the vertical component (absolute terms) in $\approx 56 \%$ of available records. Typical trends are shown in Figure 12 as a function of (a) walking frequency, (b) average speed, or (c) vertical acceleration peak, respectively.

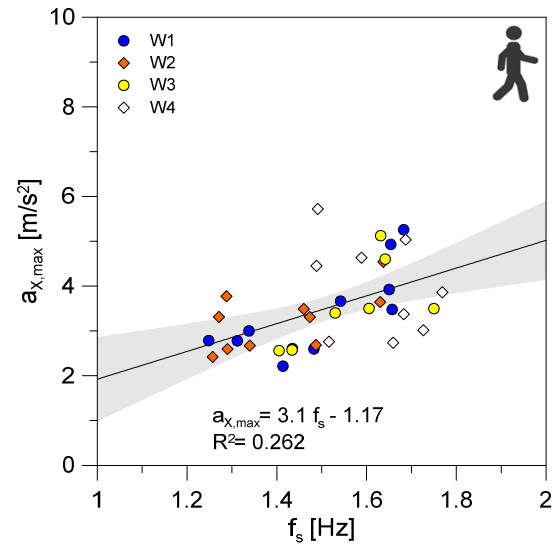

(a)

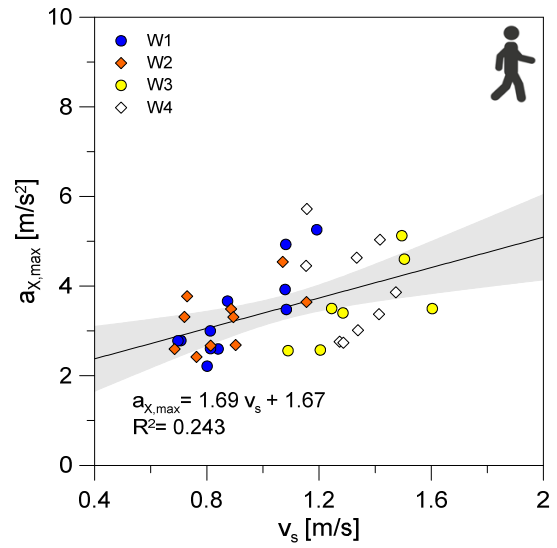

(b)

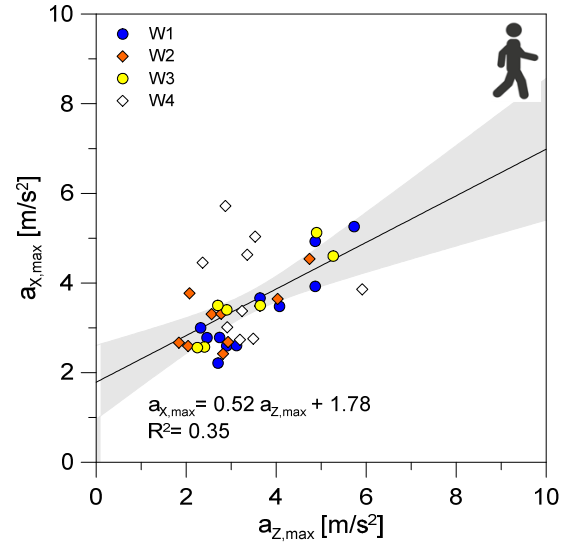

(c)

Figure 12. Summary of experimental records for W1-W4 configurations, in terms of transversal acceleration peak as a function of (a) walking frequency, (b) walking speed, and (c) vertical acceleration peak. The $95 \%$ confidence interval is shown in grey colour.

\subsection{In-Place Walks (W5)}

The analysis of experimental records was successively extended to W5 configurations characterized by in-place motion of the volunteer. Typical acceleration records were found to have, as expected, large modifications from W1-W4 conditions. An example can be seen in Figures 13 and 14 for selected data, while Figure 15 and Table 4 summarize the comparative analysis of acquired time histories. A less pronounced correlation of motion features was generally observed with walking frequency $f_{s}$. 


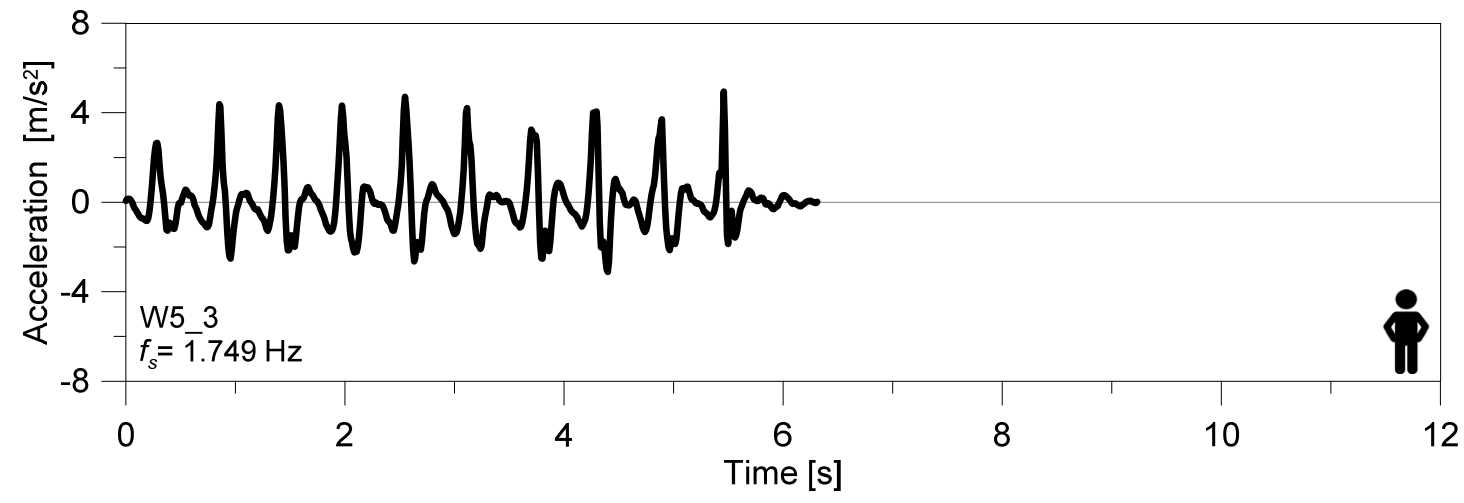

Figure 13. Example of experimental body CoM accelerations in time (W5 selection) for the volunteer on SLAB\#1.

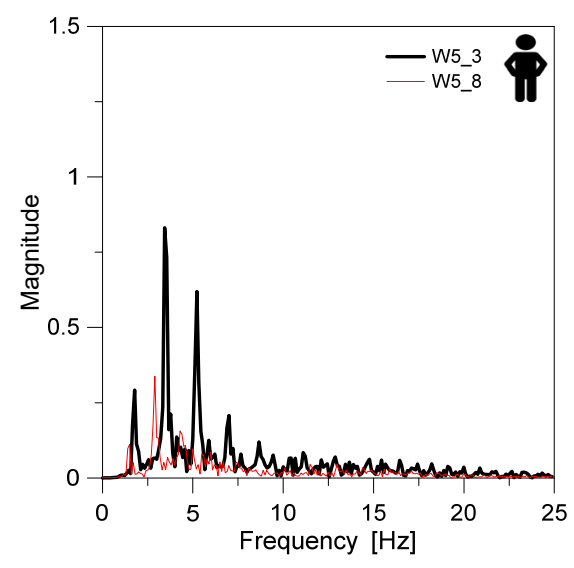

(a)

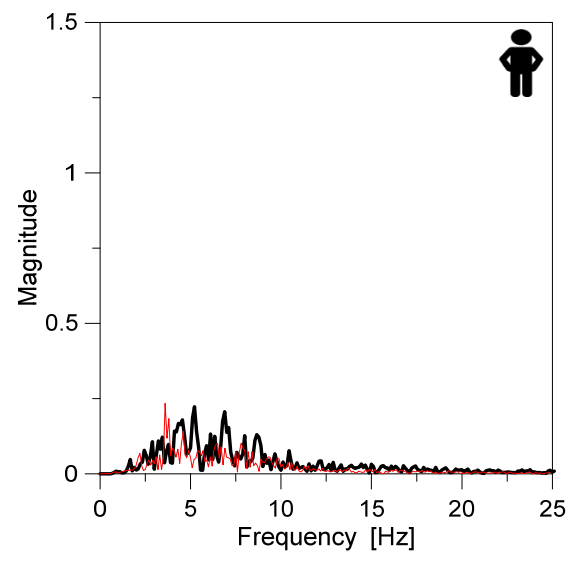

(b)

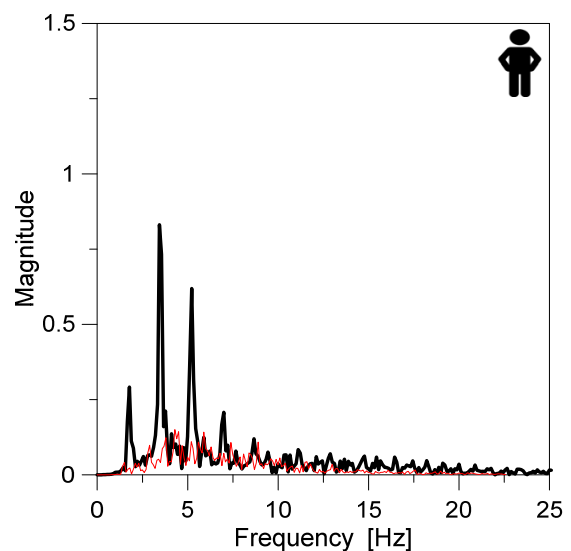

(c)

Figure 14. Analysis of experimental body CoM acceleration records (W5 selection) in terms of fast transform magnitude, with evidence of (a) vertical, (b) transversal, and (c) longitudinal components.

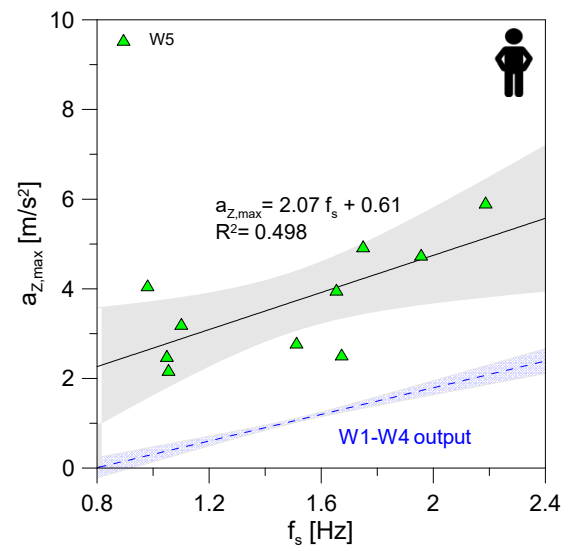

(a)

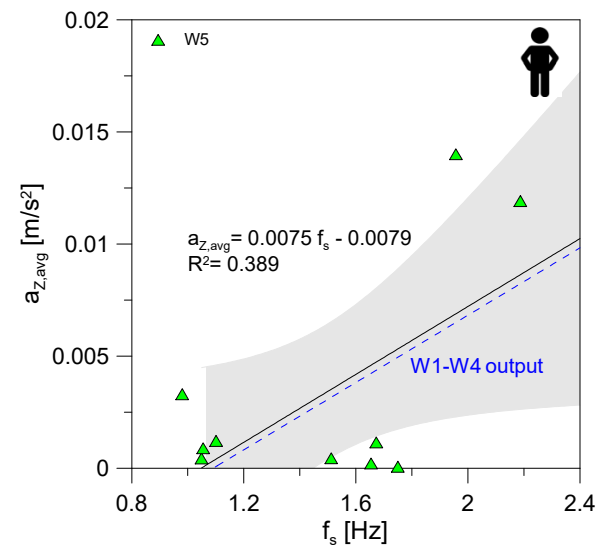

(b)

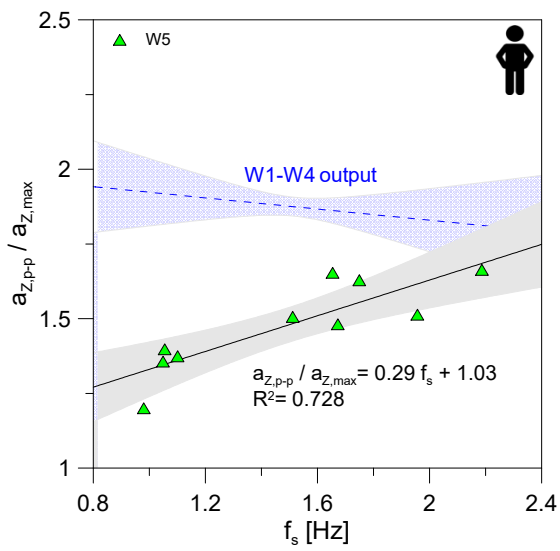

(c)

Figure 15. Summary of experimental records for W5 configurations (10 in total, SLAB\#1), as a function of calculated walking frequency: (a) peak of vertical acceleration, (b) average vertical acceleration, (c) peak-to-peak versus maximum acceleration. The $95 \%$ confidence interval is shown in grey colour. 
Table 4. Analysis of W5 vertical acceleration data (SLAB\#1, 10 samples), with standard deviation in brackets and correlation coefficient $R$.

\begin{tabular}{|c|c|c|c|c|c|c|c|c|}
\hline \multicolumn{2}{|c|}{ Frequency } & \multicolumn{3}{|c|}{ Peak } & \multicolumn{2}{|c|}{ Average } & \multicolumn{2}{|c|}{ Peak-to-Peak } \\
\hline $\begin{array}{c}f_{s} \\
{[\mathrm{~Hz}]}\end{array}$ & $\begin{array}{c}\text { Range } \\
{[\mathrm{Hz}]}\end{array}$ & $\begin{array}{l}a_{Z, \max } \\
{\left[\mathrm{m} / \mathrm{s}^{2}\right]}\end{array}$ & $\begin{array}{l}\text { Range } \\
{\left[\mathrm{m} / \mathrm{s}^{2}\right]}\end{array}$ & $R$ & $\begin{array}{l}a_{Z, a v g} \\
{\left[\mathrm{~m} / \mathrm{s}^{2}\right]}\end{array}$ & $R$ & $\begin{array}{c}a_{Z, p-p} \\
{\left[\mathrm{~m} / \mathrm{s}^{2}\right]}\end{array}$ & $R$ \\
\hline $1.491( \pm 0.425)$ & $0.980-2.187$ & $3.694( \pm 1.246)$ & $2.192-5.927$ & 0.71 & $0.0033( \pm 0.005)$ & 0.62 & $5.546( \pm 2.266)$ & 0.81 \\
\hline
\end{tabular}

As in the case of W1-W4 configurations, W5 output showed that the vertical acceleration peaks had weak linear correlation with motion frequency (Figure 15a), the average CoM acceleration was not meaningful (Figure 15b) and the peak-to-peak versus maximum acceleration ratio was rather well fitted by the linear regression model (Figure 15c). For qualitative comparison to the experimental trends of W1 to W4 configurations, previous data are also reported in Figure 15. It is possible to notice a substantial increase in the vertical component for W5 (Figure 15a), the rather close correlation of average acceleration values (Figure 15b), and the marked variation in the peak-to-peak versus maximum value ratio (Figure 15c).

In Figure 16, final comparisons are presented in terms of stride interval, with evidence of individual W5 outcomes and W1-W4 trends. As far as the average stride interval is concerned, Figure 16a shows a rather good correlation of average values for in-place walks or straight walks. Individual measurements in Figure 16b, however, show higher peaks (maximum and minimum values) for W5 configurations, compared to W1-W4 outcomes.

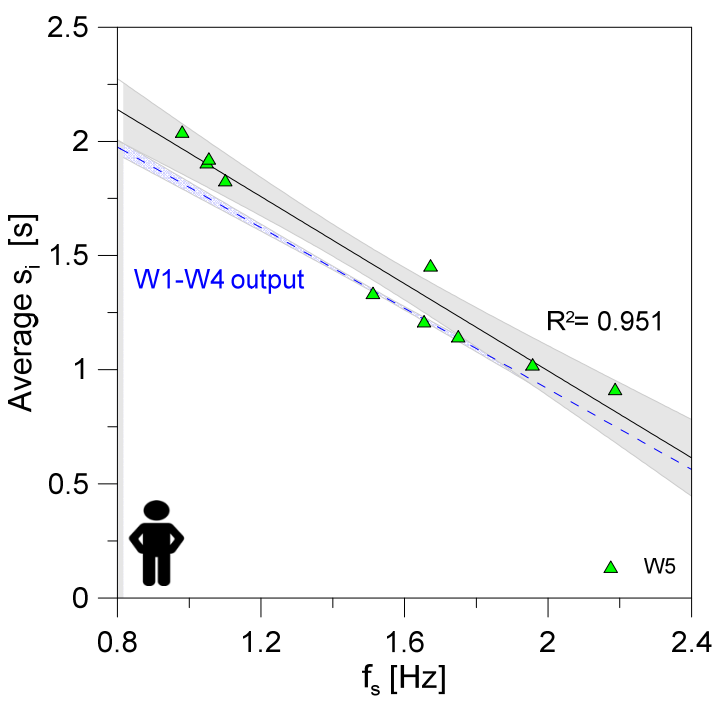

(a)

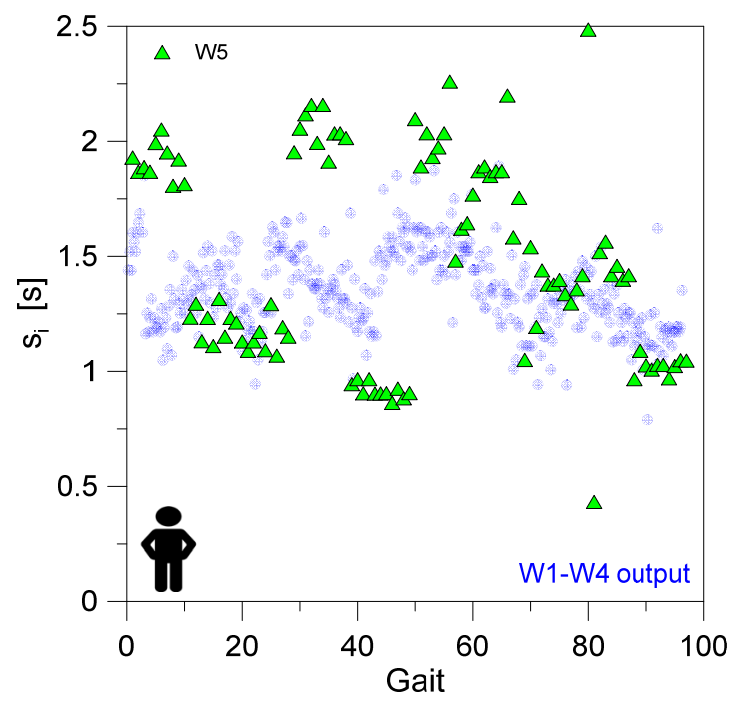

(b)

Figure 16. Summary of experimental records for W5 configurations: (a) average stride interval, and (b) stride interval variation. The $95 \%$ confidence interval is shown in grey.

\section{Structural Use of Body CoM Acceleration Signals}

\subsection{Slected Slab}

A series of finite element numerical analyses was carried out in ABAQUS [35], to quantify the effects of experimentally derived CoM acceleration time histories on the dynamic response of structural slabs. A set of geometrical nonlinear dynamic analyses was performed to predict the accelerations of pedestrian systems under random walking excitations. To this end, a concrete slab from [30], with dimensions $5 \times 6 \mathrm{~m}$ and $150 \mathrm{~mm}$ in thickness, with linear simple supports along the two maximum edges (and short edges unrestrained), was used. 
The use of the selected slab was inspired by the study presented in [30], where extended discussion of the numerical application of deterministic walking loads, as in Figure 2a, was presented. In this sense, the study in [30] was used for validation and quantitative comparison of the present body CoM input. Table 5 summarizes some major features, such as section properties, size, structural mass-to-occupant ratio $R_{M}$ (with $M=80 \mathrm{~kg}$ ), and the vertical fundamental vibration frequency of the empty $\left(f_{1, e}\right)$ or occupied slab $\left(f_{1, o}\right.$, with $M=80 \mathrm{~kg}$ ). A conventional Rayleigh approach was applied to define the mass-proportional and stiffness-proportional damping terms through parametric numerical analysis [36], with $x=3 \%$ as the damping term [30].

Table 5. Features of selected slab for the present investigation.

\begin{tabular}{ccccccc}
\hline Material & $\begin{array}{c}\text { Size } \\
{\left[\mathrm{m}^{2}\right]}\end{array}$ & $\begin{array}{c}\text { Thickness } \\
{[\mathrm{m}]}\end{array}$ & $\begin{array}{c}\text { Mass } \\
{[\mathrm{kg}]}\end{array}$ & $\boldsymbol{R}_{M}$ & $\begin{array}{c}f_{1, e} \\
{[\mathbf{H z}]}\end{array}$ & $\begin{array}{c}f_{1, o} \\
{[\mathbf{H z}]}\end{array}$ \\
\hline Concrete & $5 \times 6$ & 0.15 & 11,250 & $\approx 140$ & 7.23 & 7.1 \\
\hline
\end{tabular}

\subsection{Loading}

Each FE numerical analysis consisted of two sub-steps, the first to apply quasi-static permanent loads of structural members (gravity), and the second for dynamic analysis under the single pedestrian/volunteer.

Careful consideration was paid to quantification of the walk-induced effects of a volunteer pedestrian, based on different input signals.

As a reference:

(i) The vertical load in time due to a pedestrian was defined from experimental acceleration histories discussed previously (vertical component), with $M=80 \mathrm{~kg}$, by taking into account all the available W0 to W5 records. Acceleration time histories were applied as in Figure 17a. A total of 52 dynamic analyses were carried out.

(ii) Successively, the effect of gait variability for rough experimental body CoM input as in (i) was also numerically assessed. According to Figure 17b, an average stride record (vertical component) was derived from W1 to W4 experimental signals and fitted with different sine curves to obtain an average synthetized gait module, based on experimental measures. The so-derived synthetized stride signal was applied to the concrete slab, as in Figure 17a, and repeated to cover $n_{s}$ gaits through the total time of dynamic analyses.

(iii) For comparison, the deterministic loading approach, according to Figure $2 \mathrm{a}$, and already taken into account in [30] for the same concrete slab was also considered (with $M=80 \mathrm{~kg}$ ).

In this manner, the numerical outcomes based on present body CoM experimental accelerations were applied to a traditional solving approach for vibration serviceability analysis of pedestrian structures. Given that the conventional frequency range $f_{s}=1.5-2.5 \mathrm{~Hz}$ of normal walks was taken into account for the deterministic procedure (with $0.1 \mathrm{~Hz}$ the increment), a set of 10 nonlinear simulations was carried out in the present study for concrete slabs loaded as in (iii).

\subsection{Results}

\subsubsection{Substructure Effect (W0 Setup)}

Figure 18a shows the typical distribution of vertical accelerations under the imposed W0 walking paths, while Figure $18 \mathrm{~b}$ shows the evolution of vertical acceleration at the center of the slab. 


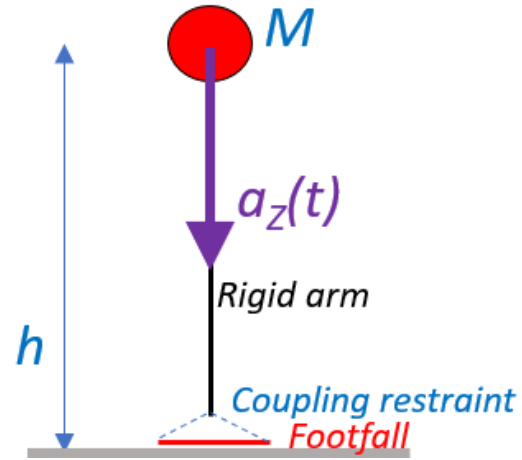

(a)

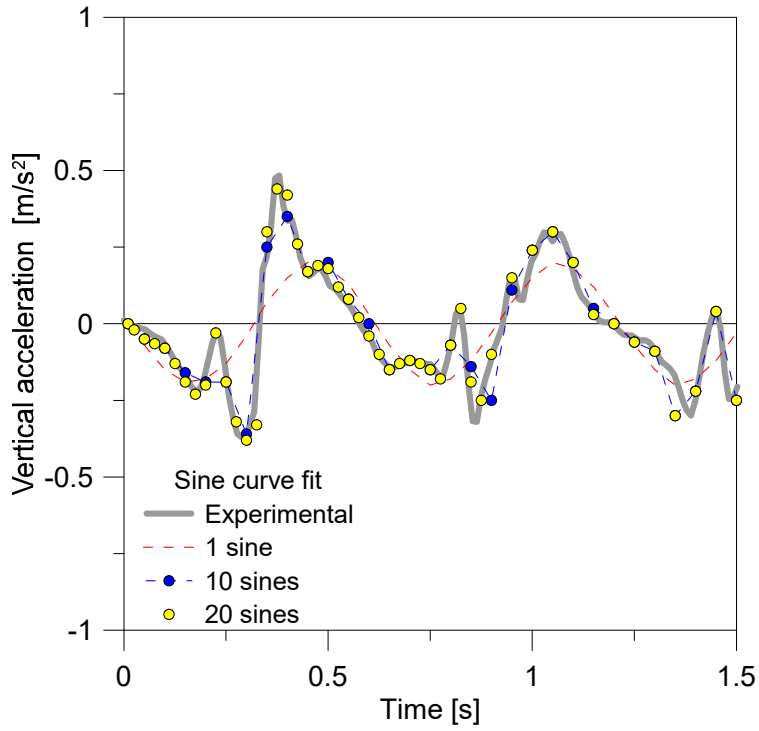

(b)

Figure 17. Loading protocol: (a) input body CoM acceleration and (b) sine curve fit of an experimental stride record (signal \#7, W1) to derive a synthetized signal.

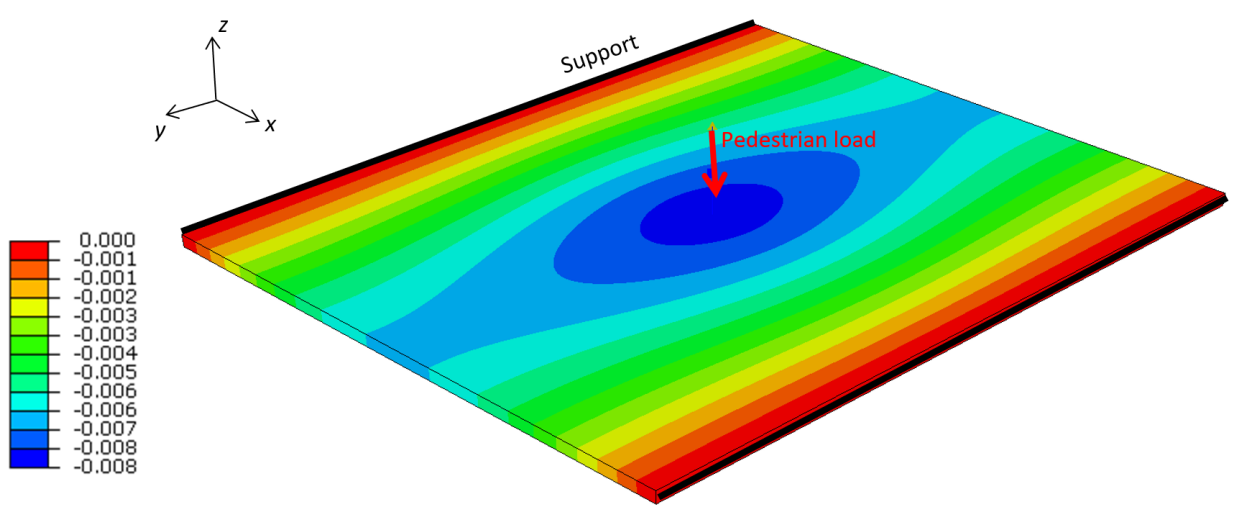

(a)

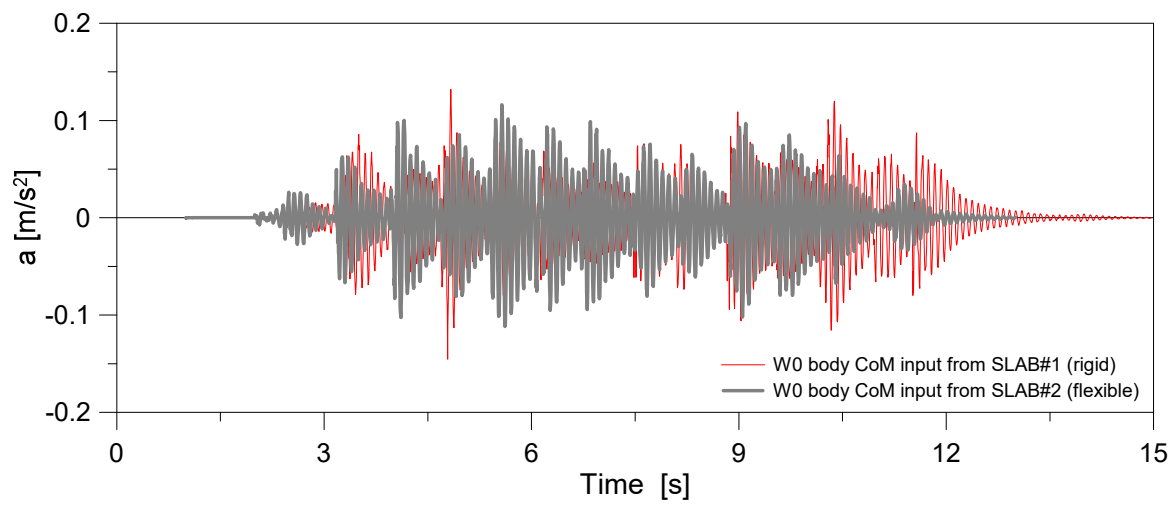

(b)

Figure 18. Summary of numerical performance indicators of the examined concrete slab under W0 experimental body CoM accelerations or deterministic pedestrian loads (ABAQUS): (a) typical acceleration distribution (values in $\mathrm{m} / \mathrm{s}^{2}$ ), with $(\mathbf{b})$ acceleration at the center of slab.

The overall performance of the concrete slab under body CoM input based on rigid substructure (SLAB\#1) could be quantified as $a_{\max }=0.14 \mathrm{~m} / \mathrm{s}^{2}, a_{p-p}=0.28 \mathrm{~m} / \mathrm{s}^{2}$, $a_{R M S}=0.0086 \mathrm{~m} / \mathrm{s}^{2}$ and CREST $=16.92$. It was shown in Section 4.1 that the available W0 signals were characterized by a mostly identical RMS value for the vertical component. 
The effect of pedestrian movement on the W0 setup with flexible support (SLAB\#2) could be quantified, on the structural side, in terms of marked modifications of performance indicators, with $a_{\max }=0.11 \mathrm{~m} / \mathrm{s}^{2}(-20 \%$ the response of the same concrete slab under W0 input on SLAB\#1), $a_{p-p}=0.23 \mathrm{~m} / \mathrm{s}^{2}(-17 \%), a_{R M S}=0.0111 \mathrm{~m} / \mathrm{s}^{2}(+30 \%)$ and CREST $=10.38(-38 \%)$.

\subsubsection{Straight (W1-W4) or In-Place Walks (W5)}

The acceleration peaks in the vertical direction $\left(a_{\max }\right)$ or the RMS value $\left(a_{R M S}\right)$ were taken into account over the time of each simulation for the slab under (i) experimental time histories or corresponding (ii) deterministic pedestrian loads. The trend of parametric results can be seen in Figure 19a,b, as a function of the input walking frequency $f_{s}$. A summary of performance indicators is also presented in Table 6. It can be seen that quite good correlations were obtained, especially for structural parameters and performance indicators based on W1 and W2 body CoM input. W5 body CoM input tended to underestimate the structural response for walking frequencies higher than $1.3 \mathrm{~Hz}$ (normal walk).

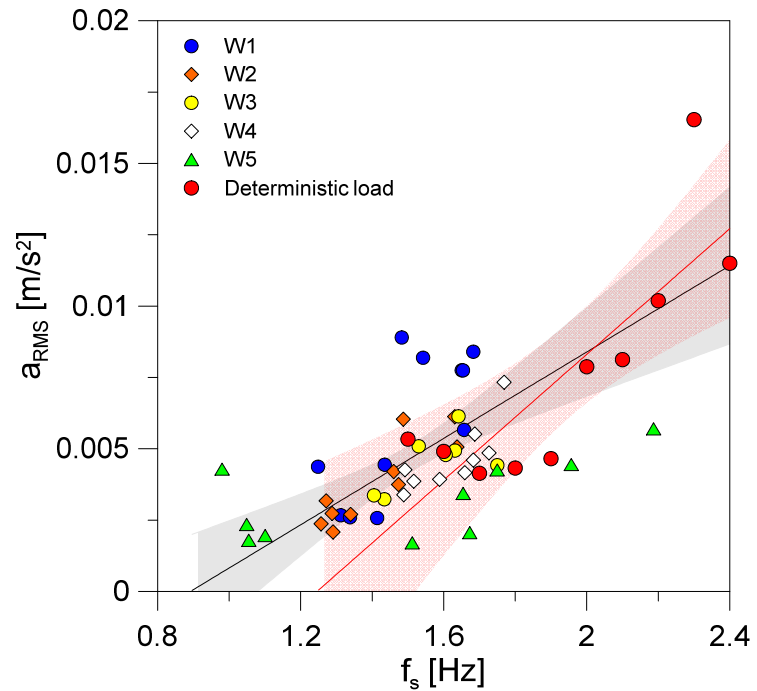

(a)

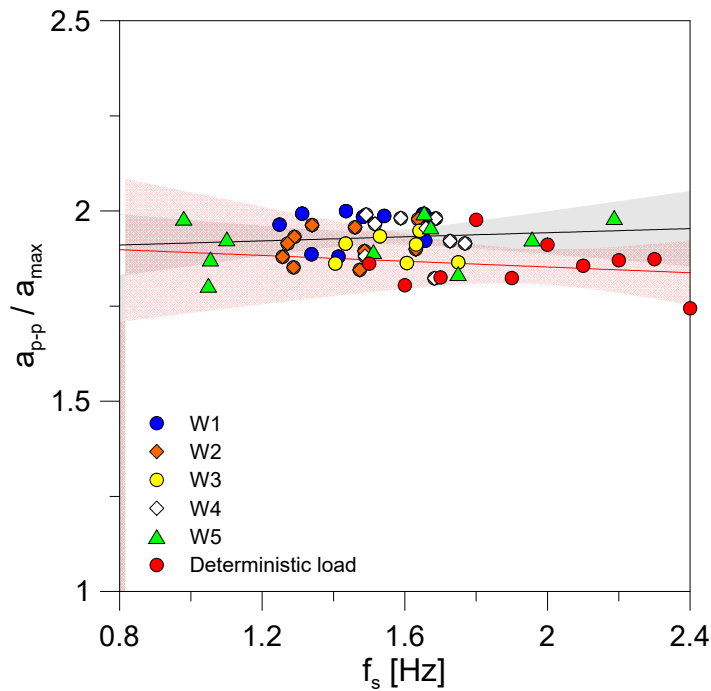

(b)

Figure 19. Summary of numerical performance indicators of the examined concrete slab under W1-W4 and W5 experimental body CoM accelerations or deterministic pedestrian loads (ABAQUS): (a) RMS value, and (b) peak-to-peak versus maximum acceleration. The $95 \%$ confidence interval is shown in grey and red colour, respectively.

Table 6. Analysis of the examined concrete slab under W1-W5 experimental body CoM accelerations, with average values of maximum, RMS and peak-to-peak vertical accelerations of slab ( \pm standard deviation) and $R$-square correlation coefficient.

\begin{tabular}{cccccccc}
\hline & \multicolumn{2}{c}{ Peak } & \multicolumn{2}{c}{ RMS } & & Peak-to-Peak \\
\hline & Simulations & $\begin{array}{c}\boldsymbol{a}_{\text {max }} \\
{\left[\mathbf{m} / \mathbf{s}^{2}\right]}\end{array}$ & $\boldsymbol{R}^{2}$ & $\begin{array}{c}\boldsymbol{a}_{\boldsymbol{R} \text { S }} \\
{\left[\mathbf{m} / \mathbf{s}^{2}\right]}\end{array}$ & $\boldsymbol{R}^{2}$ & $\begin{array}{c}\boldsymbol{a}_{\boldsymbol{p}-\boldsymbol{p}} \\
{\left[\mathbf{m} / \mathbf{s}^{2}\right]}\end{array}$ & $\boldsymbol{R}^{2}$ \\
\hline W1 & 10 & $0.098( \pm 0.045)$ & 0.78 & $0.0057( \pm 0.003)$ & 0.55 & $0.193( \pm 0.091)$ & 0.77 \\
W2 & 10 & $0.072( \pm 0.034)$ & 0.87 & $0.0038( \pm 0.001)$ & 0.77 & $0.138( \pm 0.065)$ & 0.88 \\
W3 & 10 & $0.091( \pm 0.025)$ & 0.60 & $0.0045( \pm 0.001)$ & 0.41 & $0.173( \pm 0.049)$ & 0.55 \\
W4 & 10 & $0.093( \pm 0.038)$ & 0.67 & $0.0046( \pm 0.001)$ & 0.61 & $0.180( \pm 0.072)$ & 0.66 \\
\hline Total W1-W4 & 40 & $0.088( \pm 0.037)$ & 0.63 & $0.0048( \pm 0.002)$ & 0.40 & $0.171( \pm 0.073)$ & 0.61 \\
\hline W5 & 10 & $0.068( \pm 0.029)$ & 0.41 & $0.0032( \pm 0.001)$ & 0.37 & $0.130( \pm 0.058)$ & 0.42 \\
\hline
\end{tabular}




\subsubsection{Synthetized Stride Signals Based on Body CoM Measures}

Finally, for the slab under synthetized stride signal, further comparative results are collected in Table 7 and Figure 20. The fit residual is also shown in Table 7, as the higher number of sine curves resulted in a smaller fitting error compared to the rough experimental curve. More precisely, Figure 20a shows the typical trend of vertical acceleration at the center of slab under synthetized strides from experimental records, while normalized performance indicators are summarized in Figure 20b, where each FE result is compared to the dynamic response of the slab under rough experimental stride input.

Table 7. Analysis of the examined concrete slab under synthetized body CoM stride acceleration (example for experimental stride from signal \#7-W1), with maximum acceleration, RMS value, peakto-peak acceleration, and CREST factor.

\begin{tabular}{cccccc}
\hline Body CoM Input & $\begin{array}{c}\text { Fit Residual (max) } \\
{\left[\mathbf{m} / \mathbf{s}^{2}\right]}\end{array}$ & $\begin{array}{c}\boldsymbol{a}_{\text {max }} \\
{\left[\mathbf{m} / \mathbf{s}^{2}\right]}\end{array}$ & $\begin{array}{c}a_{R M S} \\
{\left[\mathbf{m} / \mathbf{s}^{2}\right]}\end{array}$ & $\begin{array}{c}\boldsymbol{a}_{p-p} \\
{\left[\mathbf{m} / \mathbf{s}^{2}\right]}\end{array}$ & CREST \\
\hline Experimental stride & - & 0.01190 & 0.00081 & 0.02304 & 14.67 \\
Sine curve fit 20 & 0.0722 & 0.00758 & 0.00040 & 0.01473 & 18.74 \\
Sine curve fit 10 & 0.1269 & 0.00709 & 0.00042 & 0.01373 & 16.87 \\
Sine curve fit 6 & 0.1765 & 0.00466 & 0.00030 & 0.00911 & 15.51 \\
Sine curve fit 3 & 0.2909 & 0.00352 & 0.00016 & 0.00704 & 21.61 \\
Sine curve fit 1 & 0.3946 & 0.00093 & 0.00006 & 0.00182 & 16.01 \\
\hline
\end{tabular}

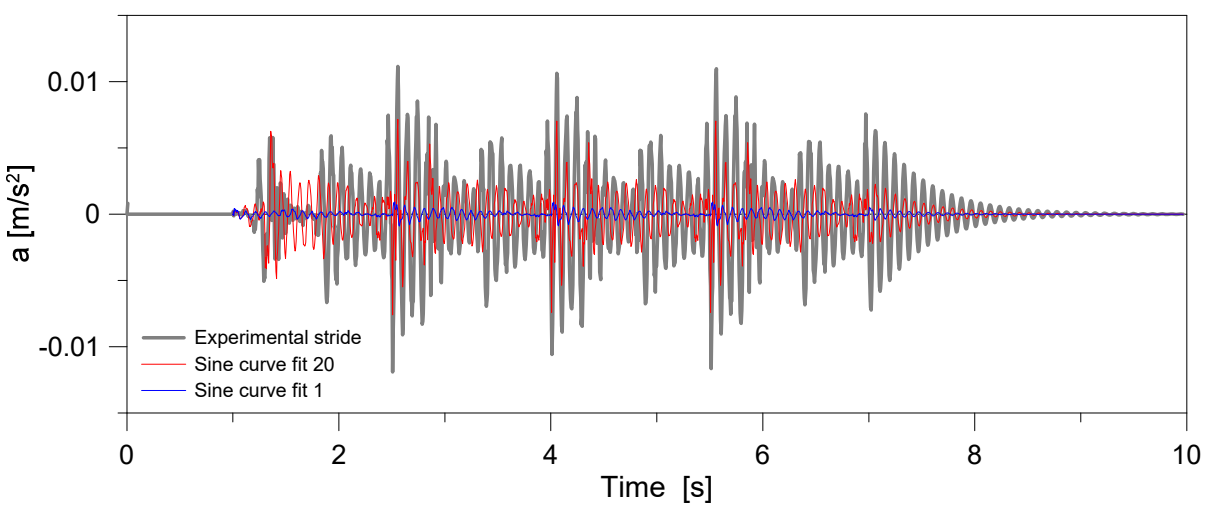

(a)

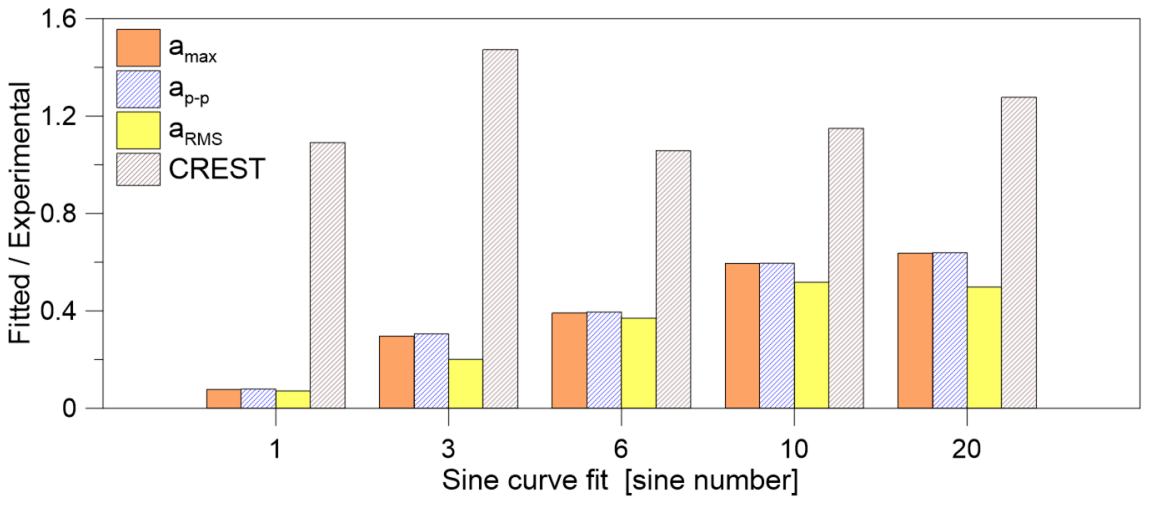

(b)

Figure 20. Numerical response of the examined concrete slab under experimental body CoM accelerations-synthetized stride signal \#7-W1 (ABAQUS): (a) acceleration at the center of slab, and (b) normalized performance indicators based on the fitted stride signal.

A rather high sensitivity of structural performance indicators can be seen in Figure 20b, compared to the rough experimental stride signal, even in the presence of relatively small residual fitting. This is also in line with numerical outcomes in Figure 19. The exception 
in Figure 20b is represented by CREST factor estimates, which are more conservative or unconservative compared to the rough experimental stride signal

\section{Summary and Conclusions}

The vibration analysis of the pedestrian system, especially for slabs with low vibration frequency, which are highly sensitive to walk-induced effects, represents an open challenge for designers. In this sense, the use of reliable pedestrian models can support efficient decision stages in design, monitoring procedures, etc., in conjunction with in-field experiments or expensive laboratory protocols. Knowledge of walk-induced effects, including a multitude of parameters, should be taken into account.

In this paper, attention was focused on the analysis of body centre of mass (CoM) motion acceleration parameters under several walking conditions, for structural analysis purposes. A total of 50 configurations was experimentally measured (for more than 500 recorded gaits) with the support of a triaxial Wi-Fi accelerometer and an adult volunteer. The sensitivity of motion parameters was explored in terms of body CoM measures, as well as in terms of the quantification of structural effects on a case-study concrete slab subjected to experimentally derived, uncoupled body CoM input.

In terms of body CoM measures, it was shown that:

- A substructure effect (W0), which results in adaptation of body movements, and thus variation of measured acceleration peaks and trends during walks, can be predicted for a given pedestrian;

- $\quad$ For straight walks on a rigid substructure (W1-W4), high variability in motion features and performance indicators was generally captured for a given walking frequency. This suggests that walking frequency alone is sometimes a weak parameter for generalization of synthetized stride models;

- The transversal acceleration component was measured in the same order or higher than the vertical component, for the majority of walking patterns;

- For in-place/stationary walks (W5), a substantial modification of body CoM acceleration parameters was observed, even under similar motion frequency and stride intervals;

- The vertical acceleration component of W5 walks was significantly higher than W1-W4 configurations.

On the structural side, the use of uncoupled body CoM acceleration input for the vibration analysis of a concrete slab showed that:

- $\quad$ Similar body CoM input (i.e., walking frequency and stride interval) but based on different substructures (i.e., rigid or flexible, as for the W0 setup) can result in strong modifications of structural performance indicators, for a given pedestrian system. In this sense, further extended scenarios should be investigated to quantify this kind of sensitivity;

- $\quad$ Body CoM input calculated from straight walks (W1-W4 setup) was generally associated with a tendency to overestimate the structural performance indicators of a given slab, compared to structural estimates for the same slab based on deterministic pedestrian loads. However, a rather close match was observed in the present study in terms of average structural effects for the examined slab (i.e., linear regression method applied to structural acceleration peaks, etc.);

- Most of the W5 body-CoM input (stationary walks) was found to underestimate a large number of examined performance indicators for the investigated concrete slab. Such an outcome was observed both for normal walking frequency, or higher frequencies;

- Finally, the derivation of synthetized stride acceleration input based on uncoupled body CoM acceleration measures was found to be severely affected by fitting accuracy, resulting in possible unsafe underestimation of structural performance indicators compared to rough experimental time histories. 
Funding: This research received no external funding.

Institutional Review Board Statement: Not applicable.

Informed Consent Statement: Informed consent was obtained from all subjects involved in the study.

Data Availability Statement: Supporting data will be shared upon request.

Conflicts of Interest: The author declares no conflict of interest.

\section{References}

1. Bachmann, H.; Ammann, W. Vibrations in Structures Induced by Man and Machines; IABSE-International Association for Bridge and Structural Engineering: Zurich, Switzerland, 1987; ISBN 3-85748-052-X.

2. Bachmann, H.; Ammann, W. Vibrations in structures induced by man and machines. Can. J. Civ. Eng. 1987, 15, $1086-1087$.

3. Sedlacek, G.; Heinemeyer, C.; Butz, C.; Veiling, B.; Waarts, P.; Duin, F.; Hicks, S.; Devine, P.; Demarco, T. Generalisation of Criteria for Floor Vibrations for Industrial, Office, Residential and Public Building and Gymnasium Halls; European Commission: Luxembourg, 2006.

4. $\quad$ Busca, G.; Cappellini, A.; Manzoni, S.; Tarabini, M.; Vanali, M. Quantification of changes in modal parameters due to the presence of passive people on a slender structure. J. Sound Vib. 2014, 333, 5641-5652. [CrossRef]

5. Setareh, M.; Gan, S. Vibration testing, analysis and human-structure interaction studies of a slender footbridge. J. Perform. Constr. Facil. 2018, 32, 040018068. [CrossRef]

6. Muhammad, Z.; Reynolds, P.; Avci, O.; Hussein, M. Review of Pedestrian Load Models for Vibration Serviceability Assessment of Floor Structures. Vibration 2018, 2, 1-24. [CrossRef]

7. Gheitasi, A.; Ozbulut, O.E.; Usmani, S.; Alipour, M.; Harris, D.K. Experimental and analytical vibration serviceability assessment of an in-service footbridge. Case Stud. Nondestruct. Test. Eval. 2016, 6, 79-88. [CrossRef]

8. Salgado, R.; Branco, J.M.; Cruz, P.J.; Ayala, G. Serviceability assessment of the Góis footbridge using vibration monitoring. Case Stud. Nondestruct. Test. Eval. 2014, 2, 71-76. [CrossRef]

9. Lee, J.H.; Park, M.J.; Yoon, S.W. Floor Vibration Experiment and Serviceability Test of iFLASH System. Materials 2020, 13, 5760. [CrossRef]

10. Bedon, C. Experimental investigation on vibration sensitivity of an indoor glass footbridge to walking conditions. J. Build. Eng. 2020, 29, 101195. [CrossRef]

11. Bedon, C. Diagnostic analysis and dynamic identification of a glass suspension footbridge via on-site vibration experiments and FE numerical modelling. Compos. Struct. 2019, 216, 366-378. [CrossRef]

12. Bedon, C.; Noè, S. Post-Breakage Vibration Frequency Analysis of In-Service Pedestrian Laminated Glass Modular Units. Vibration 2021, 4, 836-852. [CrossRef]

13. Gong, M.; Li, Y.; Shen, R.; Wei, X. Glass Suspension Footbridge: Human-Induced Vibration, Serviceability Evaluation, and Vibration Mitigation. J. Bridg. Eng. 2021, 26, 05021014. [CrossRef]

14. Shahabpoor, E.; Pavic, A.; Racic, V. Interaction between Walking Humans and Structures in Vertical Direction: A Literature Review. Shock Vib. 2016, 2016, 1-22. [CrossRef]

15. Živanović, S.; Pavic, A. Probabilistic Modeling of Walking Excitation for Building Floors. J. Perform. Constr. Facil. 2009, 23, 132-143. [CrossRef]

16. Barela, A.M.; Duarte, M. Biomechanical characteristics of elderly individuals walking on land and in water. J. Electromyogr. Kinesiol. 2008, 18, 446-454. [CrossRef] [PubMed]

17. Adamczyk, P.G.; Kuo, A.D. Redirection of center-of-mass velocity during the step-to-step transition of human walking. J. Exp. Biol. 2009, 212, 2668-2678. [CrossRef]

18. Coughlin, P.; Kent, P.; Turton, E.; Byrne, P.; Berridge, D.; Scott, D.; Kester, R. A New Device for the Measurement of Disease Severity in Patients with Intermittent Claudication. Eur. J. Vasc. Endovasc. Surg. 2001, 22, 516-522. [CrossRef] [PubMed]

19. Bedon, C.; Fasan, M. Reliability of field experiments, analytical methods and pedestrian's perception scales for the vibration serviceability assessment of an in-service glass walkway. Appl. Sci. 2019, 9, 1936. [CrossRef]

20. Bedon, C.; Mattei, S. Facial Expression-Based Experimental Analysis of Human Reactions and Psychological Comfort on Glass Structures in Buildings. Buildings 2021, 11, 204. [CrossRef]

21. Miyazaki, S. Long-term unrestrained measurement of stride length and walking velocity utilizing a piezoelectric gyroscope. IEEE Trans. Biomed. Eng. 1997, 44, 753-759. [CrossRef]

22. Veltink, P.H.; Bussmann, H.B.J.; de Vries, W.; Martens, W.L.J.; Van Lummel, R.C. Detection of Static and Dynamic Activities Using Uniaxial Accelerometers. IEEE Trans. Rehabil. Eng. 1996, 4, 375-385. [CrossRef]

23. Sabatini, A.M.; Martelloni, C.; Scapellato, S.; Cavallo, F. Assessment of Walking Features from Foot Inertial Sensing. IEEE Trans. Biomed. Eng. 2005, 52, 486-494. [CrossRef] [PubMed]

24. Godfrey, A.; Del Din, S.; Barry, G.; Mathers, J.; Rochester, L. Instrumenting gait with an accelerometer: A system and algorithm examination. Med Eng. Phys. 2015, 37, 400-407. [CrossRef] [PubMed]

25. Simonetti, E.; Bergamini, E.; Vannozzi, G.; Bascou, J.; Pillet, H. Estimation of 3D Body Center of Mass Acceleration and Instantaneous Velocity from a Wearable Inertial Sensor Network in Transfemoral Amputee Gait: A Case Study. Sensors 2021, 21, 3129. [CrossRef] [PubMed] 
26. Van Nimmen, K.; Zhao, G.; Seyfarth, A.; Van den Broeck, P. A Robust Methodology for the Reconstruction of the Vertical Pedestrian-Induced Load from the Registered Body Motion. Vibration 2018, 1, 250-268. [CrossRef]

27. Bocian, M.; Brownjohn, J.; Racic, V.; Hester, D.; Quattrone, A.; Monnickendam, R. A framework for experimental determination of localised vertical pedestrian forces on full-scale structures using wireless attitude and heading reference systems. J. Sound Vib. 2016, 376, 217-243. [CrossRef]

28. Rispens, S.M.; Pijnappels, M.; van Schooten, K.S.; Beek, P.J.; Daffertshofer, A.; van Dieen, J.H. Consistency of gait characteristics as determined from acceleration data collected at different trunk locations. Gait Posture 2014, 40, 187-192. [CrossRef]

29. Shahar, R.T.; Agmon, M. Gait Analysis Using Accelerometry Data from a Single Smartphone: Agreement and Consistency between a Smartphone Application and Gold-Standard Gait Analysis System. Sensors 2021, 21, 7497. [CrossRef]

30. Cai, Y.; Gong, G.; Xia, J.; He, J.; Hao, J. Simulations of human-induced floor vibrations considering walking overlap. SN Appl. Sci. 2019, 2, 19. [CrossRef]

31. Herzog, W.; Nigg, B.M.; Read, L.J.; Olsson, E. Asymmetries in ground reaction force patterns in normal human gait. Med. Sci. Sports Exerc. 1989, 21, 110-114. [CrossRef]

32. Wouda, F.J.; Giuberti, M.; Bellusci, G.; Maartens, E.; Reenalda, J.; Van Beijnum, B.-J.F.; Veltink, P.H. Estimation of Vertical Ground Reaction Forces and Sagittal Knee Kinematics During Running Using Three Inertial Sensors. Front. Physiol. 2018, 9, 218. [CrossRef]

33. Jiang, X.; Napier, C.; Hannigan, B.; Eng, J.J.; Menon, C. Estimating Vertical Ground Reaction Force during Walking Using a Single Inertial Sensor. Sensors 2020, 20, 4345. [CrossRef] [PubMed]

34. Beanair GmbH. BeanDevice®Wilow®User Manual_Wilow®Wireless Sensor-Version 2.3.2; Beanair GmbH: Berlin, Germany, 2019.

35. ABAQUS, Computer Software; Simulia: Dassault, RI, USA, 2021.

36. Clough, R.W.; Penzien, J. Dynamics of Structures; McGrawHill: New York, NY, USA, 1975. 